\title{
Building Integrated Agriculture Information Modelling (BIAIM): An integrated approach towards urban agriculture
}

\section{Abstract}

Urbanisation is transforming human societies in many ways. Besides bringing benefits to people in cities, it also has negative impacts such as food security. One way to meet the challenge is urban agriculture; however, traditional agricultural practices are not suitable within urban areas due to limited availability of land. Therefore, the alternative option is to grow crops inside or on top of buildings, e.g. building integrated agriculture (BIA). But, there is limited research and information available for designers and planners to design such buildings. The presented research project bridges the gap between agriculture and architecture by proposing a building integrated agriculture information modelling tool in integration with Building information modelling. The plugin tool has data on plants' requirements and automatic response to environmental factors. Environmental factors include temperature, light, water, nutrients, air, humidity, spacing and support. In this paper, seasonal tomato is selected as a reference crop, and the impact of environment (temperature, light, water, nutrients and spacing) on its health is discussed and simulated for germination stage. The undertaken project contributes to the concept of BIA and BIM maturity level, which would help to design an optimum environment building for plants.

Keywords: Urban agriculture (UA); Building integrated agriculture (BIA); Building information modelling (BIM); Greenhouses; Environmental factors; Building integrated agriculture information modelling (BIAIM); Controlled environment agriculture (CEA); Plugin

\section{Introduction}

The rapid urbanisation around the world has numerous impacts on urban society [3-6], and one of the most significant impacts is food security [7-10]. As cities grow, agricultural land is converted into residential areas [11] reducing the available cultivable land. In addition, deforestation, desertification and salinization have also altered the natural landscape of the earth, and have further intensified the problem of agricultural production and food security [12]. In contrast, arable lands cannot match the increasing deterioration [13]; when most of the available land is already being used for agricultural practices [14] . Consequently, there is massive pressure on farmers to produce more food from shrinking land [15], and there is a need to sustain agricultural sustainability and profitability without compromising ecological assets [13]. Urban agriculture (UA) is re-raised as an alternative solution to meet these challenges [16], which means bringing agriculture to urban areas. At Present, more than 800 million people are practising UA across the world [17]. UA represents food production practices that are situated inside or surrounding an urban region using human and natural resources, services, and in-situ products to cultivate, process and distributes food products [18]. 
Historically, these practices have been used in many countries, while developed countries have also started taking interest due to increasing food security problems [19]. However, in urban regions, available land is limited therefore UA can be in two ways: open rooftop farming; or high-tech controlled environment agriculture (CEA) [20], which provides ultimate results by providing optimum conditions [21].

CEA has been adopted to cultivate off-season crops and producing high-quality crops [22]. Though, for controlled environment building integrated agriculture (BIA), there is limited literature available. The key issue is the structural design of such modern BIA design; where the information on the plant-environment relationship is not available on state-of-the-art building designing tools [23-25]. For such practices to be possible, experts from various disciplines, i.e. agriculture, agronomy, architecture, urban planning, engineering, economics and public health will have to come together and work collaboratively [26]. Such intelligent collaborative platforms are also known as Building information modelling (BIM). BIM is a methodology, comprised of processes to generate and manage the information of building or group of buildings [27]. BIM can also be defined as "modelling technology and associated set of procedures to produce, communicate and analyse models" [28]. BIM tools get people and information working together effectively and efficiently through defined processes and technology [29]. Most of the developed countries have been using these tools for improvement in productivity and cost-savings throughout all stages of architectural, engineering and construction (AEC) industry [30]. Therefore, BIM is ideal for designing and managing agricultural buildings as well; and in this research, the focus is on BIM tools and objects' attributes that it contains.

BIM was introduced more than two decades earlier, which distinguished 3D information-rich model from 2D drawings [31]. Also, BIM-based tools are becoming more common in the industry and academia alike. According to National BIM Report, $54 \%$ of the AEC industry using BIM at some stage of their project, while $86 \%$ are expected to be using it in a year time [32]. Among many, Autodesk Revit and Graphisoft's ArchiCAD are leading BIM tools available [33]. These software tools not only have 3D object libraries, but also their attributes, and much useful information to help through the design, construction and maintenance phases. For example, Figure 1 shows a window object in Revit containing: physical parameters; and, analytical properties. 


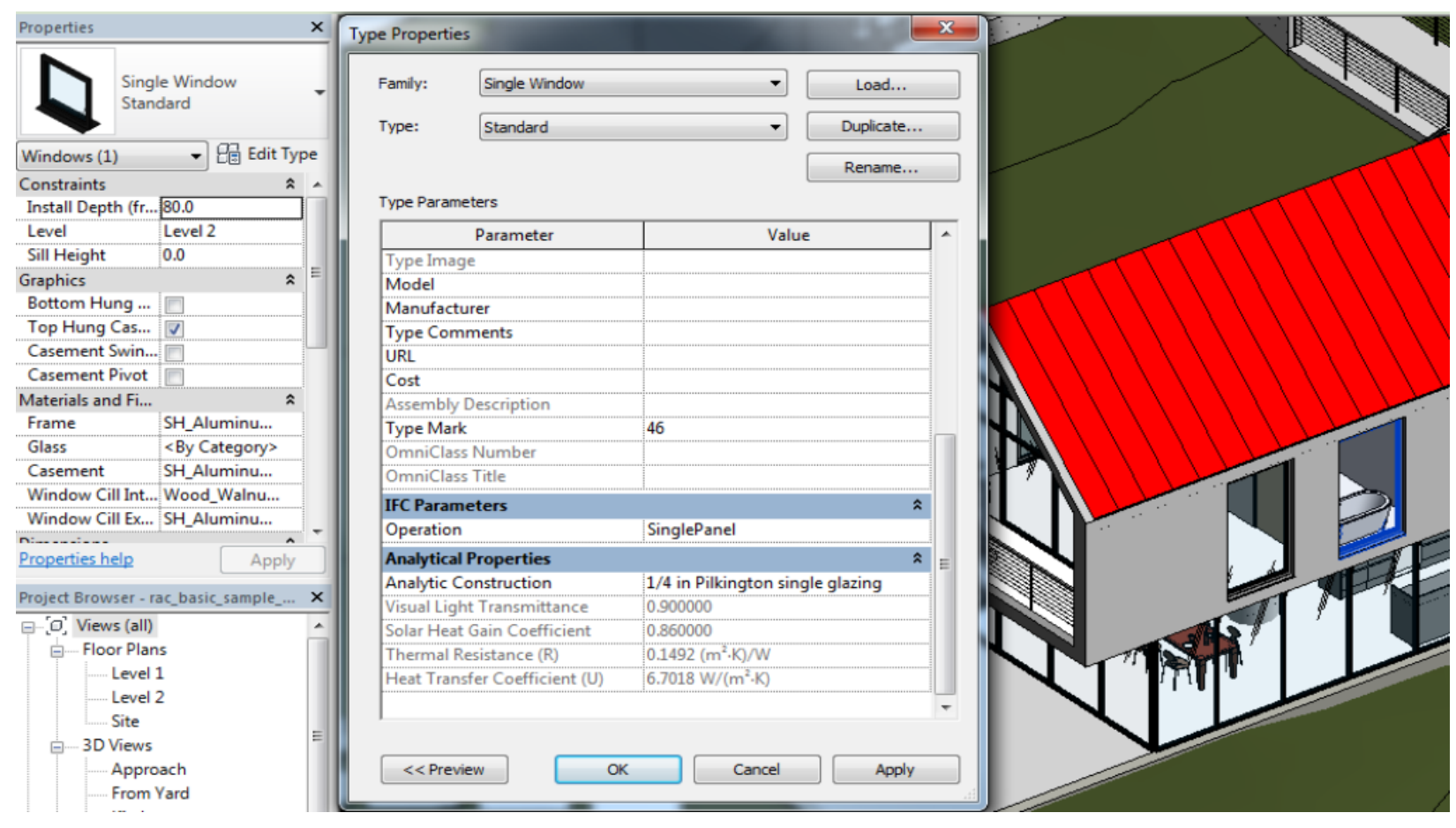

Figure 1 BIM object libraries

However, these tools do not provide intelligent plant libraries containing: plants' attributes; environmental factors; or their relationship to the environment, which could assist designers and planners to understand the plant-environment $(P-E)$ relationship and manage that information in a BIM environment. Figure 2 shows the properties of BIM plants in Revit: the only geometric component is height, which only reflects a fully mature plant; and the rest of properties are like any other building component, for example, appearance, model, manufacturer and cost. 


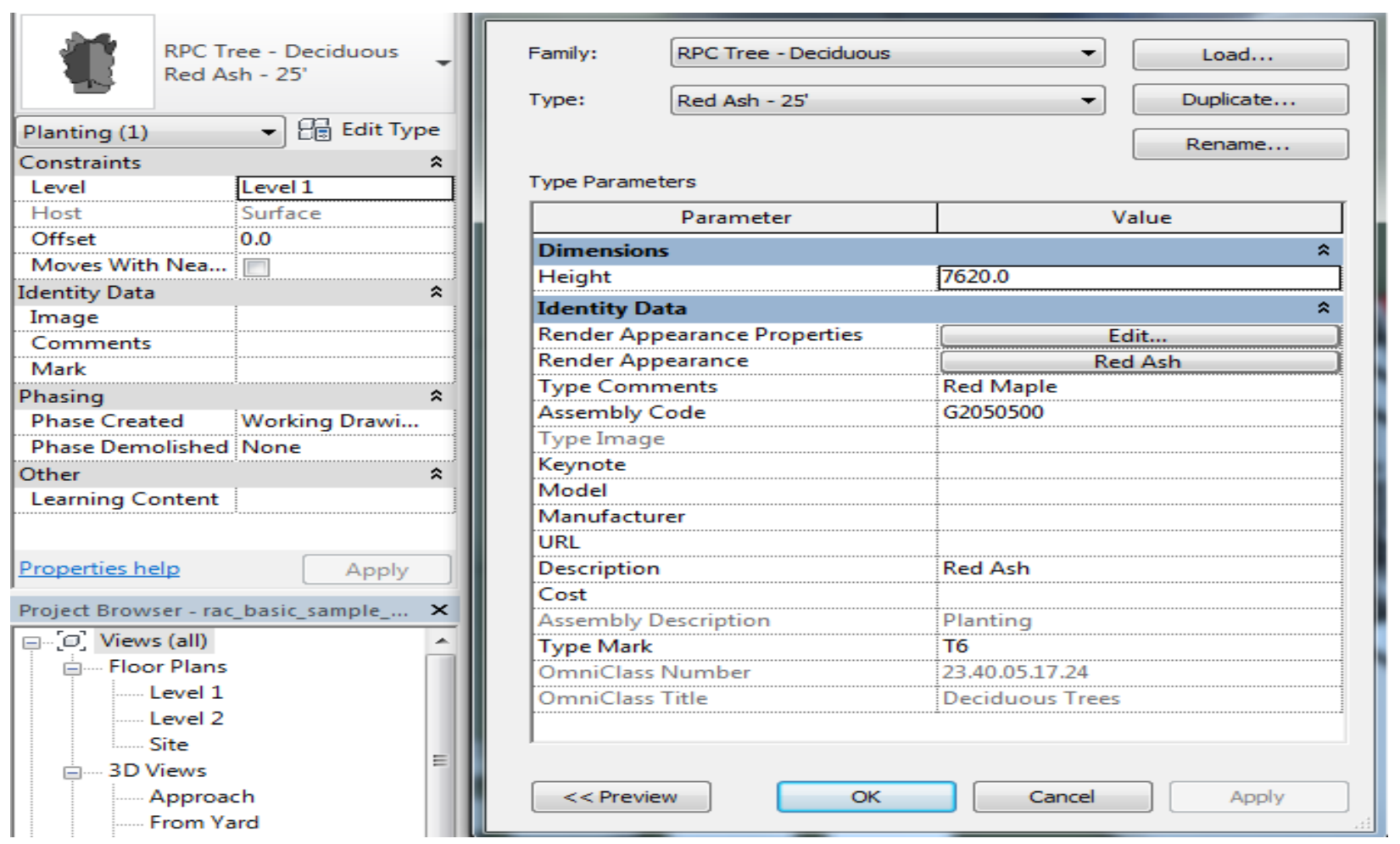

Figure 2 Plant libraries in BIM solutions

Unlike Revit, ArchiCAD does have the option to manipulate more geometric properties: height and diameter; and plants from all four season can be selected depending on the real-time condition of the site. Although it has some more features than Revit, important environmental factors: light, temperature, spacing, etc. are not considered. Similarly, Vectorworks BIM has some additional parameters, yet not enough to support through BIA design process [34]. Although, there is vital intelligence in BIM tools, however, it still is evolving and in many ways at innovation stage [35]. There are many challenges and barriers involved that are hindering the development and adoption of BIM. 1) BIM competency identification [36], 2) BIM maturity level, 3) training costs and 4) investment in new technology without the justification of potential savings [37]. This research is partially dealing with the second and partially with the fourth challenge improving the limitations of BIM plant libraries, which are summarised as follows: immature existing information, lack of analytical information, plants integration issues, plant-environment relationship, real-time simulation and limited physical properties. Therefore, this research proposes a BIA and BIM-integrated platform, building integrated agriculture information modelling (BIAIM) to design and provide environmental conditions' information for plants.

This research is a part of an ongoing doctoral research, and this paper only covers the partial development of the platform. The paper is organised as follows: Section 2 presents state of the art on UA, CEA and BIA and, BIM and its applications. Plugin development and, environmental factor and simulation analysis are discussed in Section 3. Section 4 comprises on the discussion 
of findings from the literature, and this research by pointing out factors for improvement is provided. Finally, the paper concludes with Section 5.

\section{State-of-the-art}

\subsection{Urban and Controlled Environment Agriculture}

Urban grown food has significant health benefits, and a large-scale expansion can highlight the benefits of fresh fruits and vegetables [18]. Goldstein, Birkved [38] and Goldstein, Hauschild [39] have discussed considerable advantages of UA over traditional agriculture. Among other benefits, it can provide substantial job opportunities in low and middle-income countries [40]. In addition, Choguill (1995) [41] summarised three key drivers for the development of urban agriculture: ability, necessity and opportunity; while [42] stated urban growth, environmental impact and food insecurity. Besides, unused or abandoned land also engage dwellers in utilising it for agriculture [43]. Furthermore, it can also bring significant socio-environmental benefits without increasing urbanisation pressure if implemented in neglected buildings [44], and ultimate results can be achieved if buildings provide a controlled environment.

Controlled environment facilities, also known as greenhouses, have a variety of a simple structure used for germination to a more complex controlled environment, delivering suitable environmental conditions for plants throughout the year. Hydroponic methods, where water is used as a growth medium are often referred as the complex controlled environment and also termed as controlled environment agriculture (CEA) [45]. There has been quite significant research to improve traditional greenhouses' performance; especially related to energy, which is the main concern for controlled environment. One of the prominent work has been done by Cuce, Harjunowibowo [46], who used complex engineered integrated energy and heating systems to enhance the performance of existing greenhouses. Their findings clearly showed that up to $80 \%$ of energy could be saved within 4-8 years, considering the climate and crop types. Although energy is a critical factor, it also relies on an effective mechanical, electrical and plumbing (MEP) system that provides all the resources to plants.

On MEP systems, Chauhan, Kumar [47] reviewed the work that has been done on greenhouse dryers and found that the performance of dryer under forced convection mode was found better for high moisture crops, during natural convection system for low humidity. Similarly, Esen and Yuksel [48] have designed and successfully tested a biogas, solar and ground heat pump. The system could provide optimum temperature for crops. While, to improve irrigation and heat system of the greenhouse, Hong and Hsieh [22] proposed integrated control strategy over time control, which could save up to $90 \%$ of both resources. Their research showed that maximum crop response depends on optimum environmental condition. Panwar, Kaushik [13], in their research, found that the maximum crop response depends on the optimum environmental factors that its growth. They reviewed the available literature on ventilation, cooling, heating, and thermal modelling structural analysis and experimental studies. They found that controlled environment conditions are better than open field condition for crops, e.g. increase yield, and early and higher germination rate. Lastly, they concluded their research by arguing that all year around cultivation is possible if controlled environment is provided, 
which will lead renewable and sustainable practice, especially for developing countries. Though, for creating controlled environment, all systems should be integrated with the structure

To improve the structural design, Kumar, Jha [49] tested the effect of greenhouse design on floriculture crops. They used Gerbera as a case study crop and creates a suitable microclimate for crops. The results showed that side openings and angle of roof vent influenced the model significantly. Therefore, the design of the structure is a critical component in providing optimum environmental conditions. To support the idea of closed greenhouse, Vadiee and Martin [50] proposed a conceptual closed greenhouse model to save energy. Although, they concluded considerable savings in energy, the proposed concept is neither evaluated nor considers materials' construction. In addition, plants and their environmental requirements are also not available for designers, who will select materials and design of the structure. Nevertheless, the study provided enough analysis to support the concept of building integrated greenhouse. It also incentivises that controlled greenhouses can be multi-storey and will be more economical and productive. Whereas, on a commercial level, high demand for energy can be met by using fuel cell technology along with other renewable technologies [51]. Perhaps greenhouses can be built more resilient using open control systems like Groener, Knopp [52] described in their research.

\subsection{Building Integrated Agriculture (BIA)}

Although there is limited literature available on BIA; however, the idea is not new, and there are many aeroponic and aquaponics building integrated farms exist [14, 53]. Most farms do not have specific agricultural structures and are built in abandoned buildings. For example, world's largest building integrated greenhouse has grown over 250 types of green crops and selling more than 20 at commercial level [54], which is built in an abandoned building. BIA can benefit in designing truly sustainable cities by incorporation of a more detailed evaluation of the land, water and energy consumption during food production, delivery and disposal processes. Hydroponic systems are one of the most efficient forms of BIA [55]. Furthermore, if crops are grown vertically using hydroponic systems, the farm can generate 20 times more yield and only uses $8 \%$ of water compared to traditional practices [56]. Table 1 shows some of the existing hydroponic farms in the world. 


\begin{tabular}{|c|c|c|c|c|c|c|c|}
\hline Location & Owner & Details & $\begin{array}{c}\text { Location } \\
\text { type }\end{array}$ & Crop Type & Area $\left(m^{2}\right)$ & Energy Source & Source \\
\hline $\begin{array}{l}\text { South } \\
\text { Korea }\end{array}$ & $\begin{array}{c}\text { Rural development } \\
\text { authority }\end{array}$ & $\begin{array}{l}\text { Three stories tall } \\
\text { experimental }\end{array}$ & Rural & Lettuce & 450 & Grow light & Alter [57] \\
\hline Japan & $\begin{array}{l}\text { Plant factories } \\
(50+) \text { Nuvege }\end{array}$ & $\begin{array}{l}\text { Commercially } \\
\text { successful }\end{array}$ & $\begin{array}{c}\text { Peri- } \\
\text { domestic }\end{array}$ & Lettuce & 5295 & $\begin{array}{l}\text { Half use sunlight } \\
\text { and rest grow light }\end{array}$ & $\frac{\text { http://agriculture. }}{\text { com }}$ \\
\hline Singapore & Sky Greens & $\begin{array}{l}\text { Commercial four } \\
\text { stories tall }\end{array}$ & $\begin{array}{l}\text { Inside the } \\
\text { city limits }\end{array}$ & $\begin{array}{l}\text { Chinese } \\
\text { Cabbage, } \\
\text { Spinach, } \\
\text { Lettuce, etc. }\end{array}$ & $\begin{array}{c}70 \\
\text { (expanding) }\end{array}$ & Sunlight & $\frac{\text { http://www.skygreens. }}{\text { com }}$ \\
\hline Chicago & Farmed Here & Commercial & $\begin{array}{l}\text { Inside the } \\
\text { city limits }\end{array}$ & $\begin{array}{c}\text { Baby green, } \\
\text { Broccoli, and } \\
\text { Kale }\end{array}$ & 5574 & Uses sunlight & Robarts [60] \\
\hline
\end{tabular}


Among several existing forms of BIA, Rooftop Greenhouse (RG) farming is the most popular since rooftops represent a significant unutilized urban area, and lightweight hydroponic greenhouses do not necessitate any major structural reinforcement of buildings. Several North American companies have already proven that substantial amounts of food can be produced year-round for urban dwellers on unutilized rooftops in dense urban settings where free and affordable land is exceptional [61]. Rooftop farms or gardens have been in practice for many years, and they are operating as the proof of concept. Currently, New York City (NYC) is at the foreground of BIA rooftop farms, for example, $40000 \mathrm{ft}^{2}$ Brooklyn Grange Farm and $6000 \mathrm{ft}^{2}$ Eagle Street Rooftop Farm, which have produced and a wide range of crops [45]. This approach can have a significant contribution to the environment, food security and economy if adopted at a greater variety.

Sabeh [62] mentioned benefits like low energy consumption, stormwater management, heat island reduction, carbon sequestration and building insulation. Specht and Sanyé-Mengual [63] and Specht, Siebert [64] reviewed existing literature on rooftop agriculture, which illustrates its benefits, limitations, potential and contribution to the community if right policies are put together. Nonetheless, each type of BIA has its advantages and constraints, for example, vertical hydroponic plants have limited height available, and higher crops cannot be suitable; and it has a higher yield, low water and nutrient requirement. In a case study, Pons, Nadal [65] found that BIA produced tomatoes are cheaper, having lower environmental impact and have sufficient cultivation temperature due to building's thermal inertia. Although BIA has started getting attention recently, there are currently no adequate tools available to design a building that has intelligent plant libraries to assist through planning, design and management process. Nonetheless, smart tools like BIM has the potential to host such libraries.

\subsection{Building Information Modelling (BIM)}

BIM has been assumed and defined in many ways, and its versatility has caused discussion about its validity and applicability. It has been considered a methodology and set of processes to digitally represent and exchange the knowledge and information about construction projects, providing decision support throughout its lifecycle [66]. In addition, BIM can enhance not only the processes but also have the capability to facilitate alternative approaches [67]. BIM process and workflow is shown in Figure 3. The workflow shows how BIM methodology can assist throughout the project; from evaluation to maintenance. With a variety of systems, BIM is transforming the way projects are designed, engineered, deliver, manage and maintain [68]. In conjunction, it is a process that runs throughout the life of an asset. Bradley, Li [69] summarised BIM as a concept, process and methodology comprising on four key elements: collaboration, representation, process and lifecycle; all are interrelated to provide efficient and innovative project platform. While [70] has discussed BIM process throughout the lifecycle: design, construction and management. 


\section{BIM Workflow}

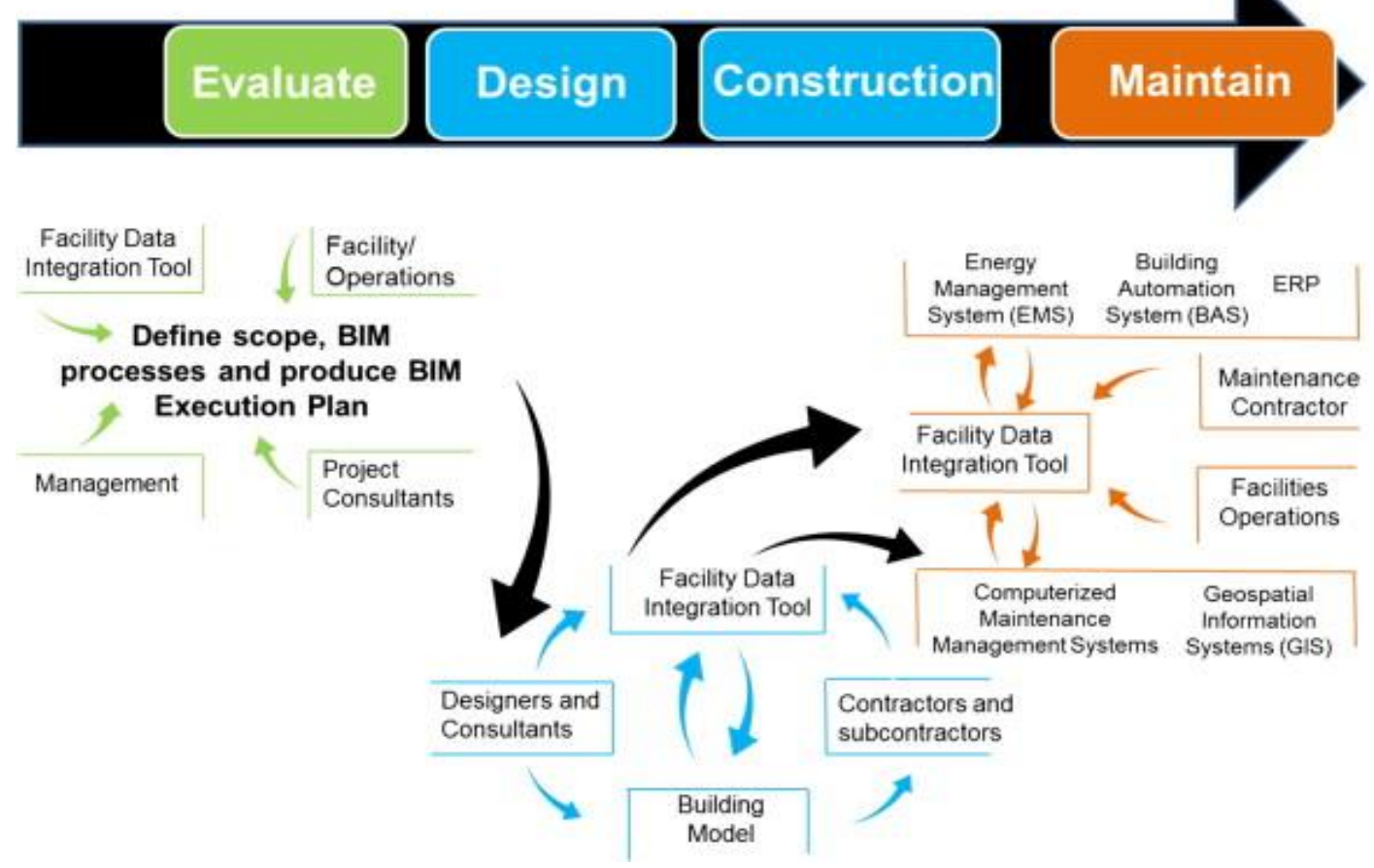

Figure 3 BIM lifecycle workflow [Source: Love, Matthews [71]]

BIM provides a platform to gather both graphical and nongraphical information of the building project, which focuses on the possibilities of utilisation of that information than what it contains. In addition, it comprises the tools and technologies to improve the collaboration in the construction industry, which enhances the productivity by improving planning, design, construction, maintenance and management [33], whereas 3D graphics and related information have broadened the knowledge of the user [72]. BIM tools can also help to effectively design, simulate and validate multidisciplinary (i.e. architectural, structural, electrical, mechanical, plumbing and ventilation) projects on a single platform [70, 71].

This versatility makes them ideal for designing a building integrated greenhouse that would need all these systems. In addition, it has intelligent objects [75], and customization of these tools can improve the design process efficiency, and minimises designers' efforts on additional and recurring activities. BIM provides significant benefits to the facility designers and owners and users such as solar and energy analysis, better environment, water efficiency and owner's satisfaction [74, 76]. Although, BIM is transforming AEC industry by providing precise, suitable and related information throughout the lifecycle of a building. Conversely, it has not been fully adopted, which can be divided into four levels: starting from level 0 to level 3 (CAD drawing to fully integrated) as shown in Figure 4. 


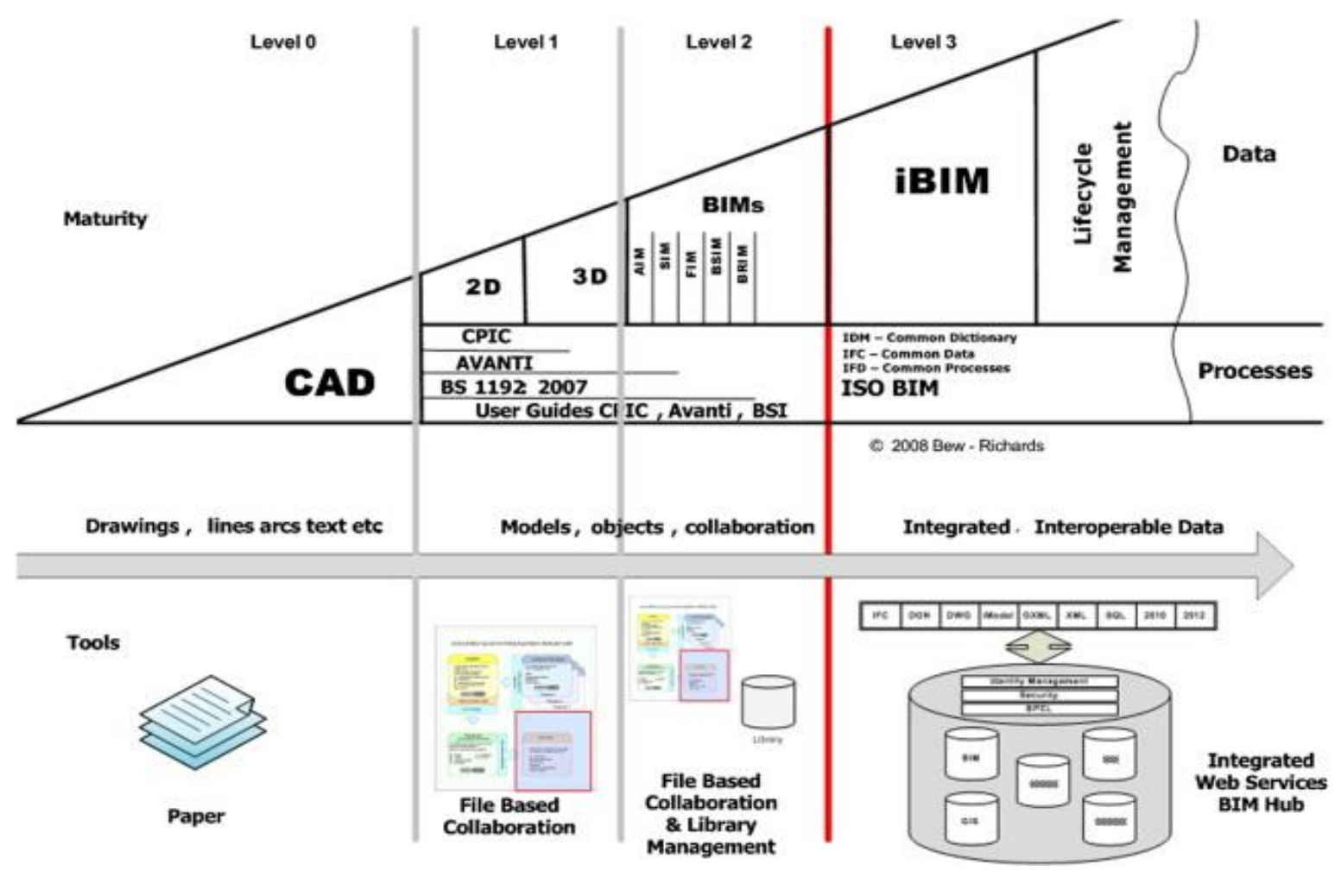

Figure 4 BIM adoption [Source: [77]; (Less than 5\% 3D CAD has building information modelling [78, 79])]

The majority is still working on level 1 that is 2D-3D modelling; while others are on level 2, and getting significant benefits from it by utilising it as a tool for advanced visualisation and collaboration [79]. While the potential of BIM for facility management is yet to be exploited; however where adopted, the advantages are very significant [80]. Therefore, considering its significant potential, in this research, we stimulate the potential of BIM for BIA facilities.

Some Architects believe that it is sensible to bring farming where everybody lives [81]. The idea is that a building integrated greenhouse will be able to produce crops all over the year, providing safe, high-quality and fresh food. Within a greenhouse, environmental factors can be controlled to provide optimum growth condition. Environment factors include the following: temperature, water, light, nutrients, space, air, humidity and support [78-82]. First five factors are considered in this research, and are further explained in section 3.1. The concept of hightech UA is still in its infancy to conclude its applications and socioeconomic success at a global level [14]. In contrast, this concept will reduce transportation expenses and $\mathrm{CO}_{2}$ emissions linked with delivering the food to distant locations [87]. In summary, to achieve the benefits of $\mathrm{UA}$ and BIA, BIM's multidisciplinary platform can also be integrated to design and manage agricultural facilities, which will not only exploit BIM potential but also enhance its maturity. 


\section{Building Integrated Agriculture Information Modelling (BIAIM) Plug-in Development}

The proposed framework has three main components: database development, which contains the information on environmental factors, plants attributes and Plant-Environment (P-E) relationship; BIAIM user interface development, which has three modules to visualise, analyse and manage data; and integration of BIAIM and BIM. The BIAIM development framework is shown in Figure 5.

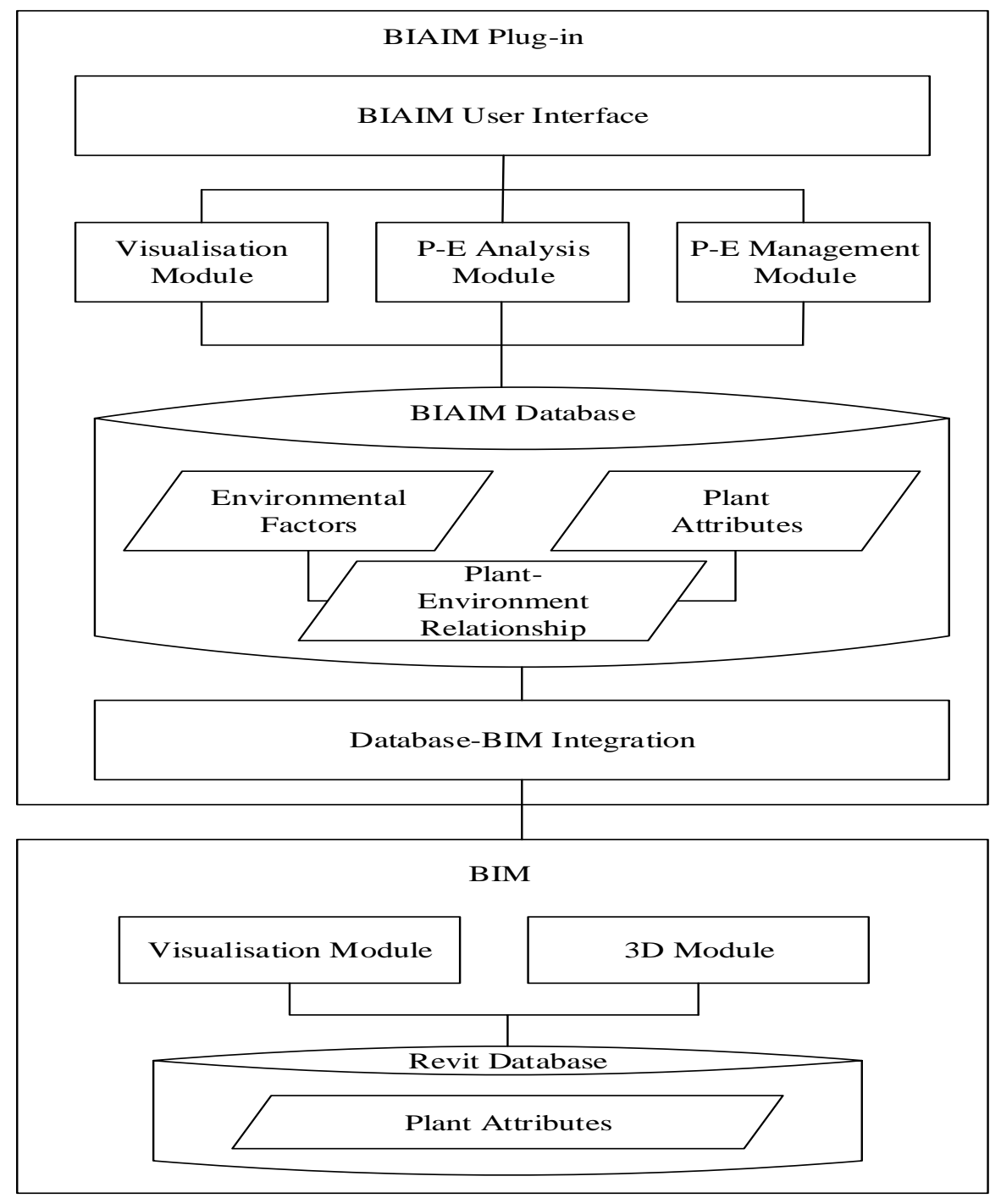

Figure 5 BIAIM Plug-in Development Framework

Environmental factors need to be considered and analysed prior to the development of the database. While building components that will be affecting the plant growth are HVAC, Lights, Site, Space and growing media $[88,89]$ can be designed in BIM tools. All these components influence plant growth directly by influencing the environment, therefore, having an impact on plants' growth. For BIAIM database, P-E relationship study provides an insight how various 
plant species have different environmental requirements. In this study, the seasonal tomato is selected as a case study crop. Although, every crop has four stages, initial, development, middle and final. At this juncture, the initial (seedling germination stage) is selected as it's the first stage of the process. Simulation and sensitivity analysis are conducted to analyse the environmental impact on germination. The data is stored in a SQL database, and for visualisation, Autodesk Revit (BIM) is selected as Revit also uses SQL database. Along with .NET framework, Revit API is used to develop the BIAIM plugin and its user interface, and link the databases.

\subsection{Database Development}

For database development, the understanding plant-Environment relationship is critical. Data was collected from various sources including universities and research companies, which is appropriately referenced in relevant sections. Environmental factors have a direct impact on plant's health, therefore, will act as input variables in the analysis. The database structure is shown in Figure 6. Though, at this point, only five factors: temperature, irrigation, nutrients, light and spacing are analysed.

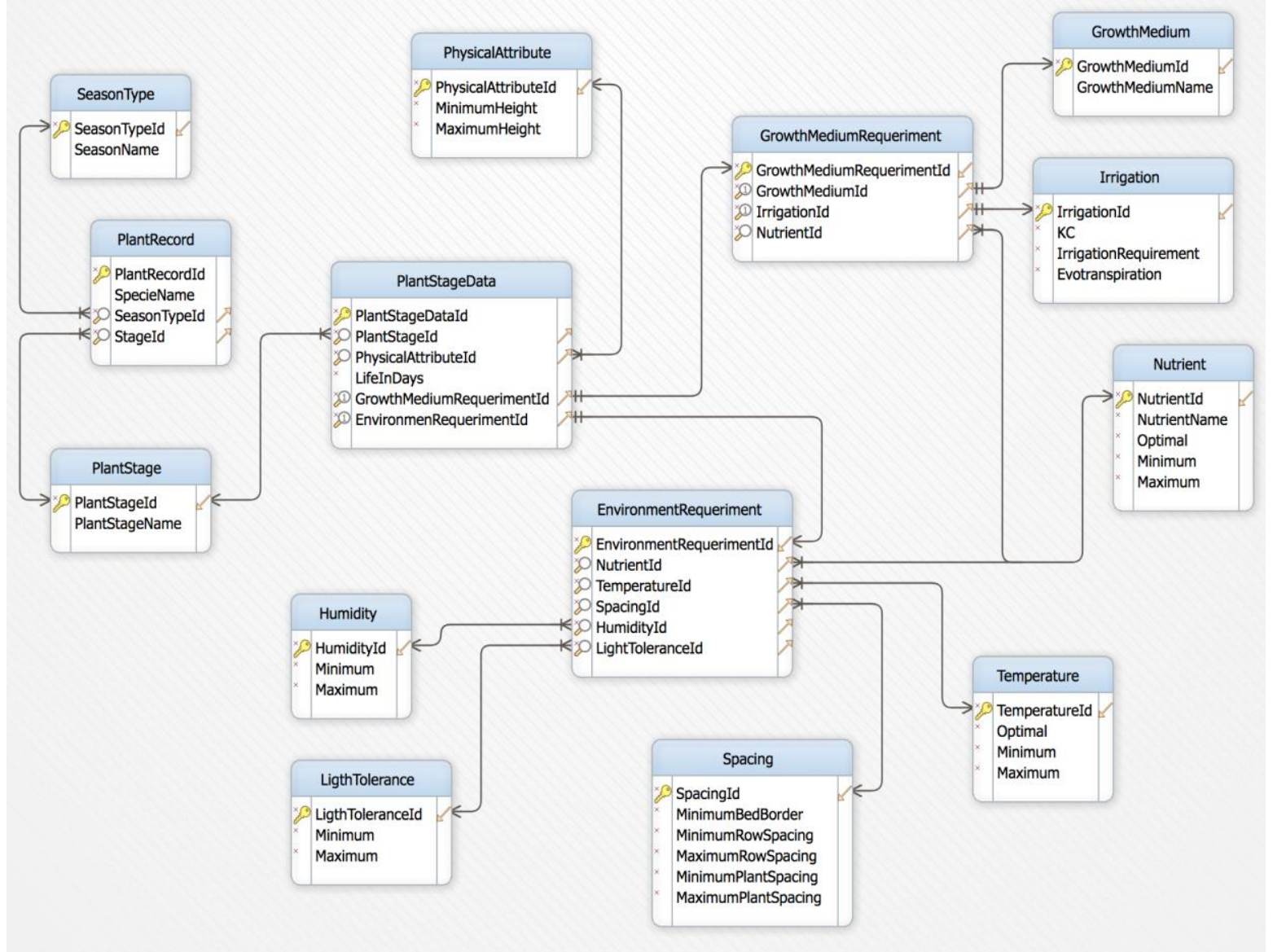


The database has following three main components: environmental factors; plants' attributes; and plants' environmental requirements. The requirement depends on the type and growth stage of the plant, and factors are interrelated: any variance in one may vary other factors. Environmental factors for a seasonal tomato crop over its lifespan are analysed in the following sections.

\subsubsection{Environmental Factors' Analysis}

a) Temperature: Temperature is one of the most important factors to influence plant growth [90]. Figure 7 shows temperature requirements for warm summer tomato crop [2], which is a member of Solanaceous crop family. The growth level is a theoretical assigned value ranging from 0 (no growth) to 1 (perfectly normal). The Figure also shows that the optimum temperature is 80 . Plant health and fruit production can be caused if the temperatures are too high (above $90 \mathrm{~F}$ ) or too low (below $55 \mathrm{~F}$ ) [90].

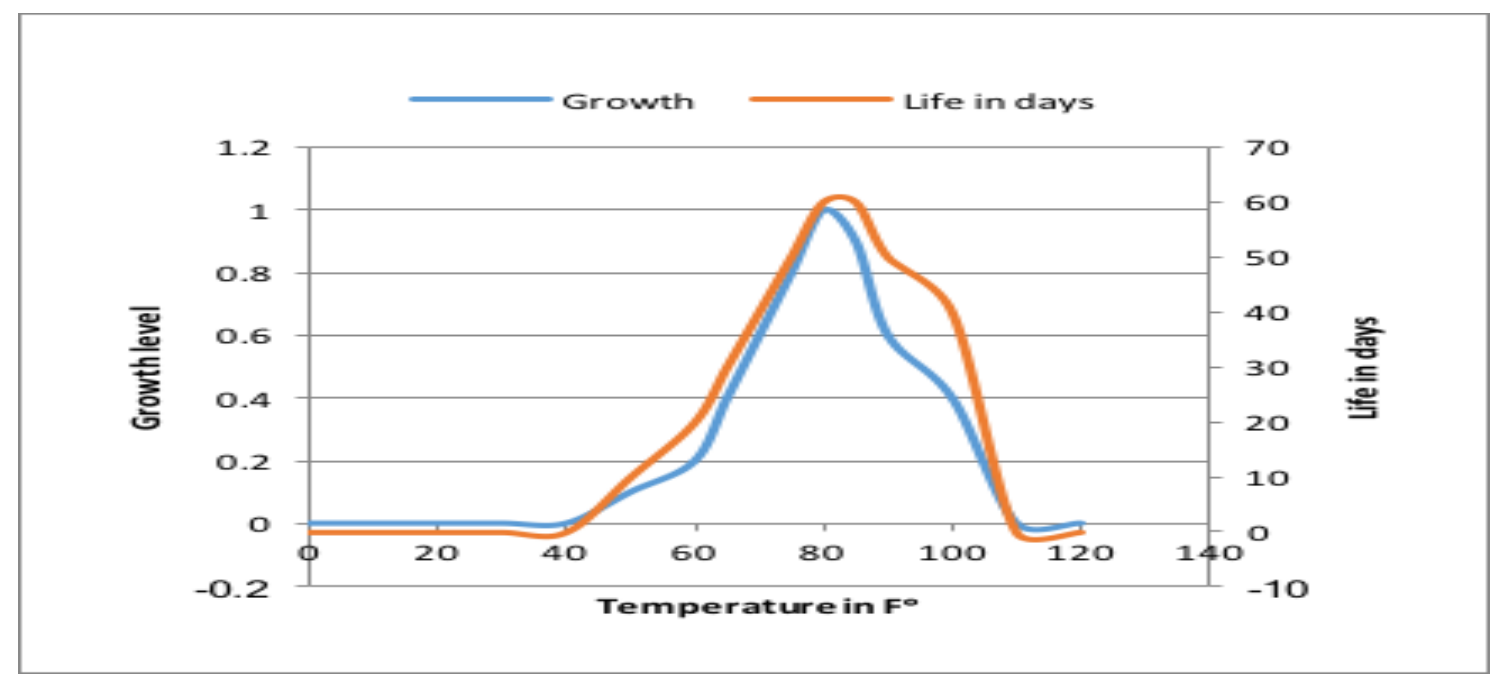

Figure 7 Temperature requirement for Tomato crop

b) Irrigation: Two different terms are used for irrigation, and it is important to distinguish between crop water requirement and crop irrigation requirement. The crop water requirement $(C W R)$ is the amount of water used by a a crop for cell construction and transpiration, while the irrigation requirement (IR) is the amount that is provided during irrigation to ensure that crop receives the required amount of water (CWR) [91].

The net irrigation can be estimated using following equation:

$$
I R_{n}=E T_{c}-(P e+G e+W b)+L R_{m}
$$

Equation 1

Where:

$I R_{n}=$ Net irrigation requirement $(\mathrm{mm})$

$E T c=$ Crop evapotranspiration $(\mathrm{mm})$

$P e=$ Effective dependable rainfall $(\mathrm{mm})$ 
$G e=$ Groundwater contribution from water table $(\mathrm{mm})$

$W b=$ Water stored in the soil at the beginning of each period $(\mathrm{mm})$

$L R_{m n}=$ Leaching requirement $(\mathrm{mm})$

In the current situation, as it is a controlled environment system, therefore:

$P e, G e$, and $L R_{m n}$ are not affecting plants directly, hence, are ignored. Subsequently, the only contributing factors are $W_{b}$ and $E T_{c}$. The amount of water stored in the soil can be measured by using different methods that are available in [91], which are not in the scope of this research; or if the growth medium is other than soil. Therefore, the only factor that needs measuring is $E T_{c}$, and at this point, this is the only factor that is considered and will be measured. Considering all constants and ineffective factors, equation 1 can be written as

$I R_{n}=E T_{c}$

Equation 2

And $E T_{c}$ can be measured by using following equation.

$E T_{c}=K_{c} * E T_{o}$

Equation 3

Where:

$K_{c}=$ Crop evapotranspiration coefficient

$E T_{o}=$ Reference Crop evapotranspiration ( $\mathrm{mm} /$ day)

On the other hand $K_{c}$ varies from crop to crop and stage to stage, details are available in [92]. However, as a case study, as seasonal tomato crop is selected as a reference and its $K_{c}$ value is shown in Figure 8, whereas for soilless CEA, $E T_{c}$ estimation can be studied in [93]. 


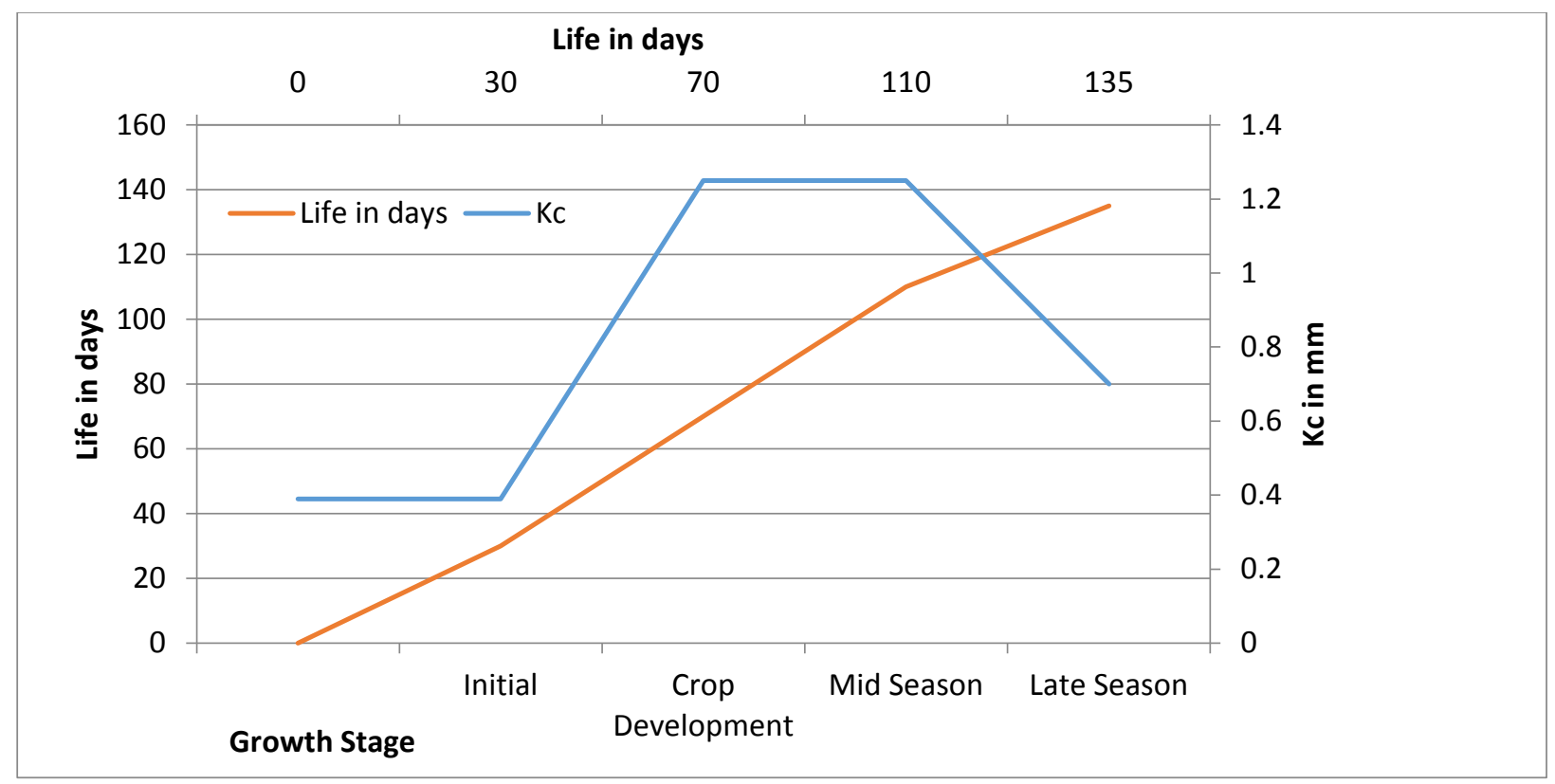

Figure $8 \mathrm{Kc}$ for Tomato crop under standard conditions

"life is days" represents the overall life span of a seasonal tomato crop. Now, $E T_{c}$ can be estimated using Equation 3 where the average values of $K c$ for humid environment are used to estimate $E T_{c}$ for tomato crop. However, these values depend on environmental conditions, for example, [93] results showed that $K_{c}$ value was almost equavalent to 1 , which makes $E T_{c}=E T_{0}$. However, both conditions meet Equation 2; $I R_{n}=E T_{c}$.

c) Nutrients: Nutrients are another critical component for plants and their uptake for seasonal Tomato crop is shown in Figure 9. Although there are minor nutrients as well, however, at this stage, we are only considering macro nutrients. For example, oxygen is the first nutrient that a seedling requires to germinate. However, that is present in the air. The data shows that Potassium has the highest percentage followed by Nitrogen. In contrast, Potassium is the least required nutrient. However, it is the most important during the initial stage of plant's life. 

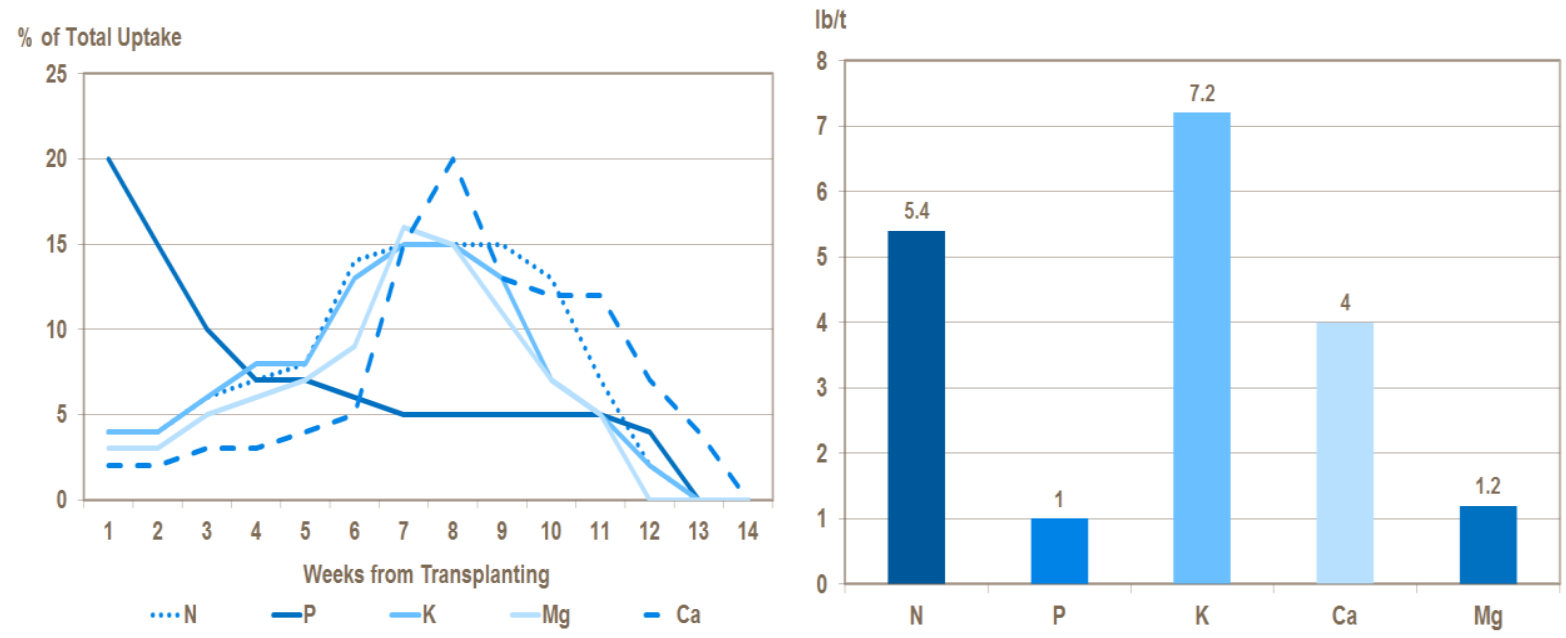

Figure 9 Tomato plant nutrients uptake [1]

d) Light: Light is an essential component for photosynthesis [2], and in the absence of light this process stops and plants breath like humans. The photosynthesis rate will be higher if a plant receives more sunlight but up to a limit. The typical light duration is between 10 to 12 hours $[94,95]$. If low light plants are moved to a bright location, the sun will scorch the leaves. Over time, as the wax content on leaves increase, they will become more sun tolerant. Light requirements for various conditions are shown in Figure 9.

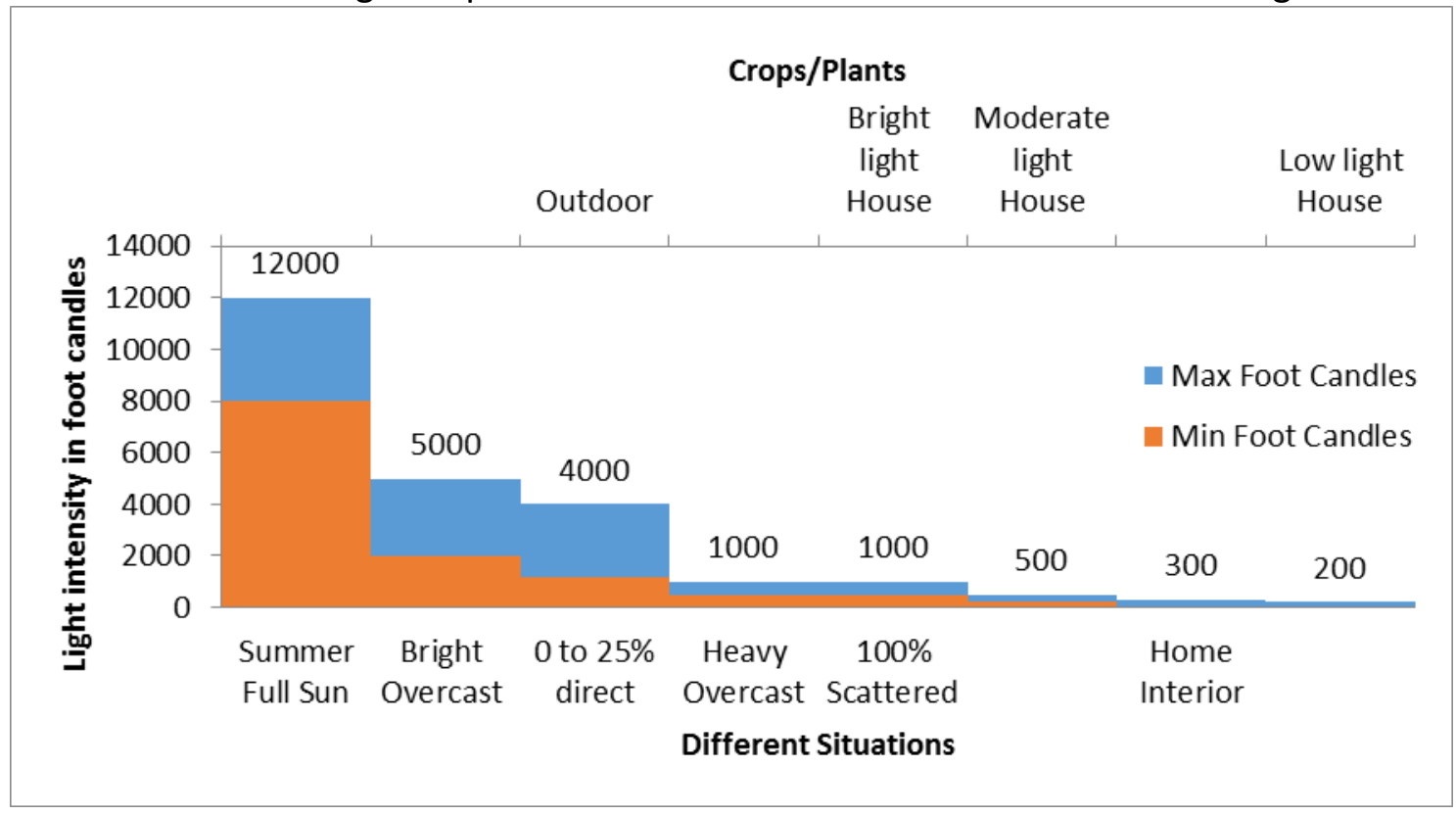

Figure 10 Light intensity for various situations [2]

For Tomato, the light requirement is $20-30+\mathrm{mol} / \mathrm{m}^{2} /$ day $[96,97]$ (equivalent to 1157 to 2319 foot-candles). This amount can be provided in a greenhouse by using both natural and artificial 
light sources. Although, these conditions depend on the geographic location and vary from location to location. However, the minimum required amount of light can only vary for different species of the same plant.

e) Spacing: Space can affect crop growth and yield, so it is important to leave the appropriate space between plant to plant and row to row. Usually, crops require more space between rows compared to between plants. For instance, tomatoes require between 24-26 inches plant to plant and 24-48 inches row to row spacing and could be cultivated in a square $[89,98]$.

Although, all factors have an impact on plant, however, the two most important environmental variables for seedling germination are temperature and water [95-99], and the impact can be better understood using simulation and sensitivity analysis.

\subsubsection{Simulation and Sensitivity Analysis:}

The entire life span of a plant can be simulated under various environmental conditions, however, for now, only germination stage is considered, which can be regarded as a pre-initial stage of plant life. Over last two decades, the growth of computer resources has helped scientist and researchers to develop plant growth models efficiently [94]. The very basic concept of computer simulation of plant growth is discussed in Jaeger and De Reffye [104]. Advanced level of modelling at various stages are reviewed by Prusinkiewicz [105], and they mentioned that the simulation modelling is new, yet becoming a fascinating area of research. Merks, Guravage [106] discussed plant modelling using Virtual Leaf software. The article may be referred for detailed review around the virtual modelling of plants' architecture. These tools mainly integrate various disciplines like applied mathematics, life sciences, environmental sciences and computer sciences. The focus of this section of the project is to simulate and analyse the impact of environmental factors on seedling germination stage. Theoretical impact values are assigned to simulate the impact of environmental factors. Table 2 shows theoretical impact values for above mentioned 5 factors that might have a minor or severe impact on the plant during its germination stage.

Table 2 Impact values for Environmental factors

\begin{tabular}{lrr}
\hline Input factor & Factor Impact value(F) & Random Number (RN) \\
\hline Temperature & 0.38 & 1 \\
Water/Irrigation & 0.36 & 0.784237182 \\
Light & 0.04 & 0.938496496 \\
Nutrients $\left(\mathbf{O}_{\mathbf{2}}\right)$ & 0.20 & 0.569366925 \\
Space & 0.02 & 0.370168586 \\
\hline Total & 1 & \\
\hline
\end{tabular}

All impact values are assigned based on their importance for germination, which can be found in [95-98]. The simulated effectiveness of factors is estimated by Monte Carlo Simulation, 
whereas the sum of environmental factors impact value is approximately 1 . The theoretical germination time (G.T) can be calculated by the following equation.

$$
G . T=\text { Min.Time }+[\mathrm{Lag}] *\left[F_{1} * R N_{1}+\cdots+F_{n} * R N_{n}\right]
$$

Lag is the difference between the minimum and maximum time to germinate, which in this case is 3 days. The results are graphically represented in Figure 11.

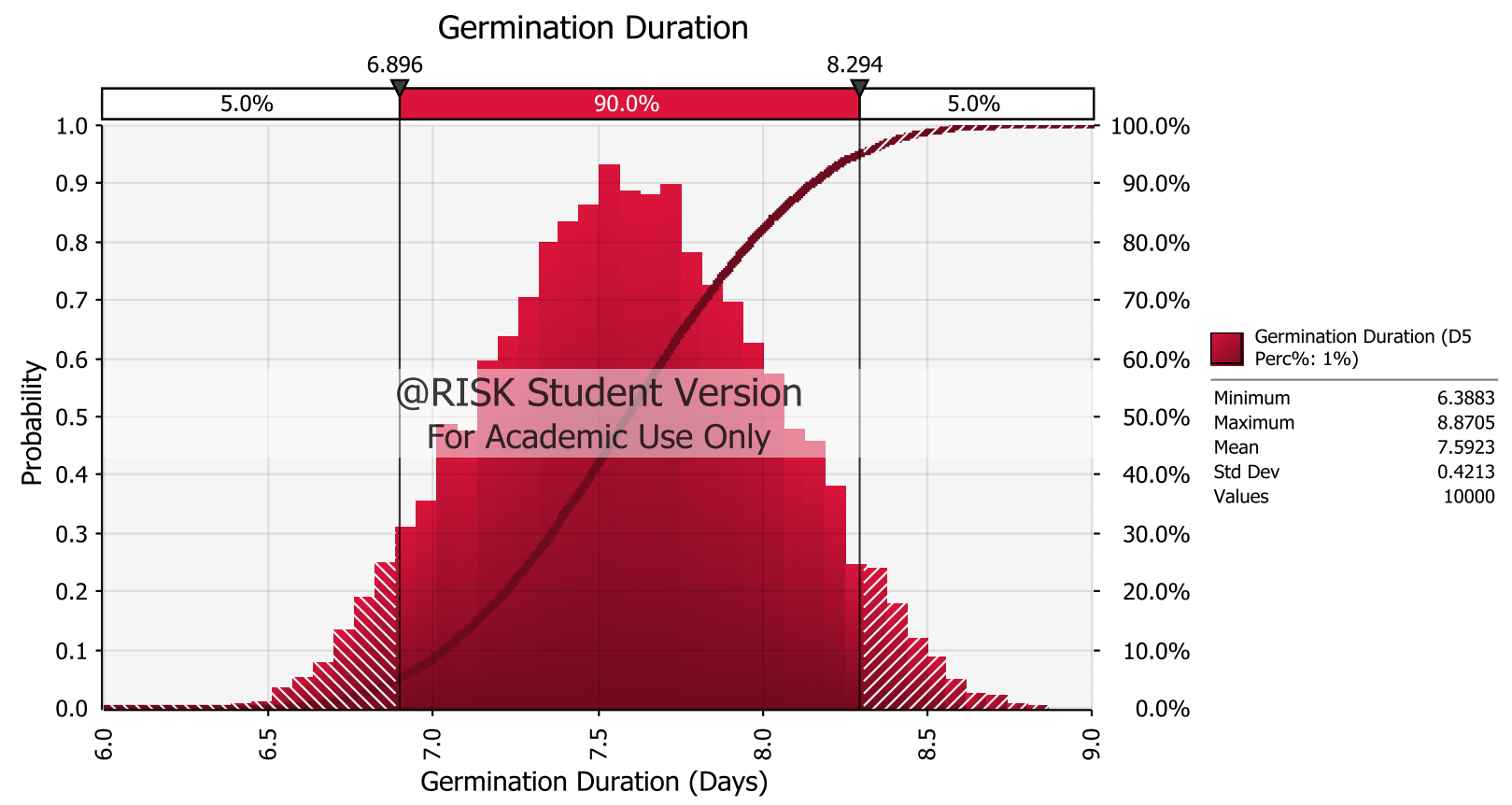

Figure 11 Graphical distribution of input risk factors

Results show that there is a $90 \%$ probability that seeds will be germinated between 7 to 9 days. The minimum value represents ideal conditions, and the optimum duration will be 6 days. However, all values are assumed to be within minimum and maximum required for the process. As a consequence, the coefficient value of input factors is decreased because it does not have any influence on the minimum duration, as shown in Figure 12. Similarly, coefficient values show their minimal impact on the germination time. However, if these conditions vary, the germination time may rise to 10 days, which proves the scenario of maximum germination duration. 


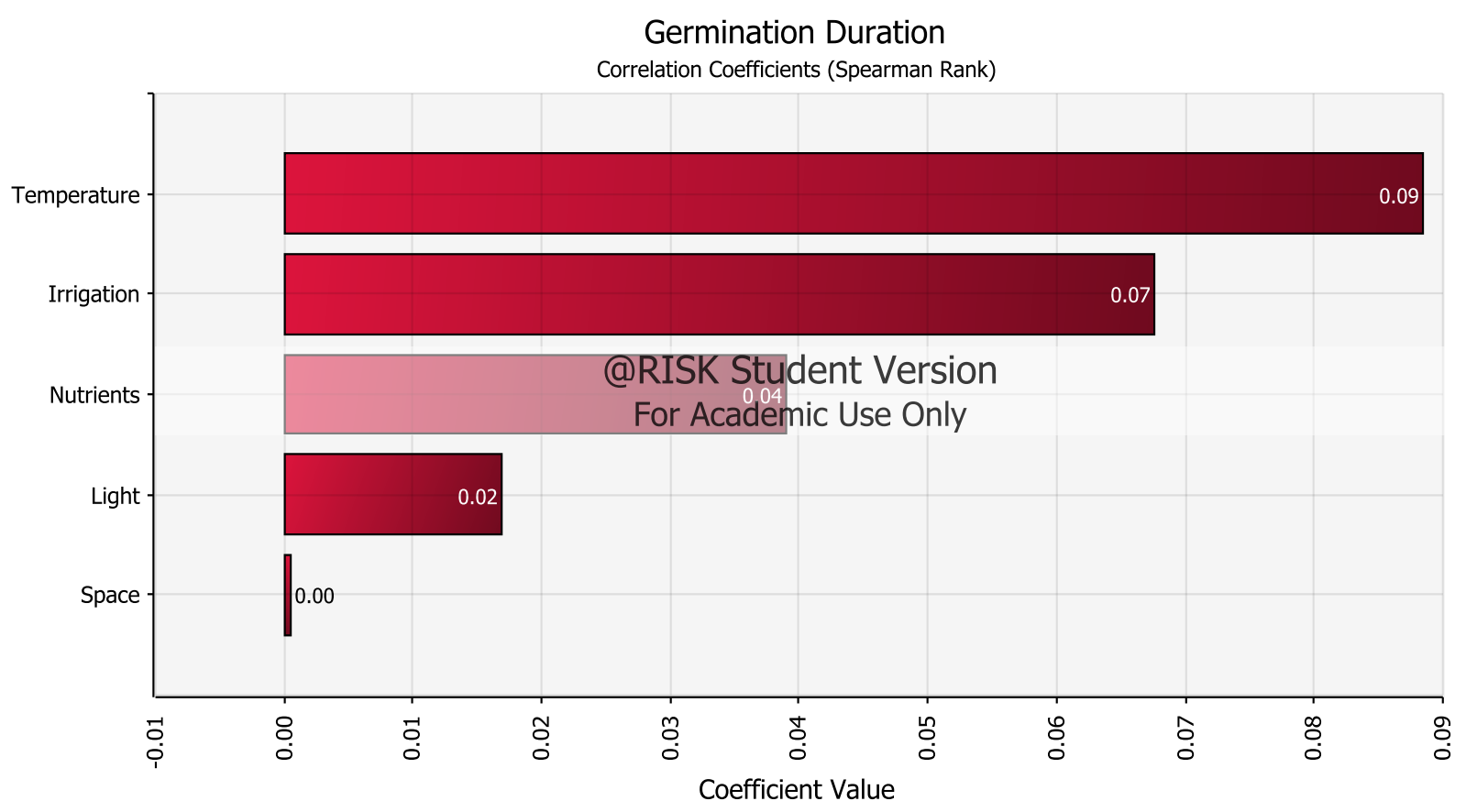

Figure 12 Correlation coefficient values

Sensitivity analysis is carried out to analyse the impact of any change to environmental factors, which are temperature, water, light, nutrients and space, and are affecting the germination duration. Figure 13 shows the percent change in environmental factors and their impact on the germination duration. Figure 13(a) represents the percent input change of variables and their effects on the germination mean duration. If the temperature is considered, it is affecting the germination from the very start and stays until the end of germination; while light has the minimum impact on the process. A more comprehensive way is to represent any change in environmental factors and represent it accordingly, and Figure 13(b) shows that relationship between input and output values. Results also demonstrate the relationship between percentage change of environmental factors and mean of germination duration. For negative change value, the average duration is reducing, and for positive, it is increasing. Evidently, the temperature has the highest impact on the process. 


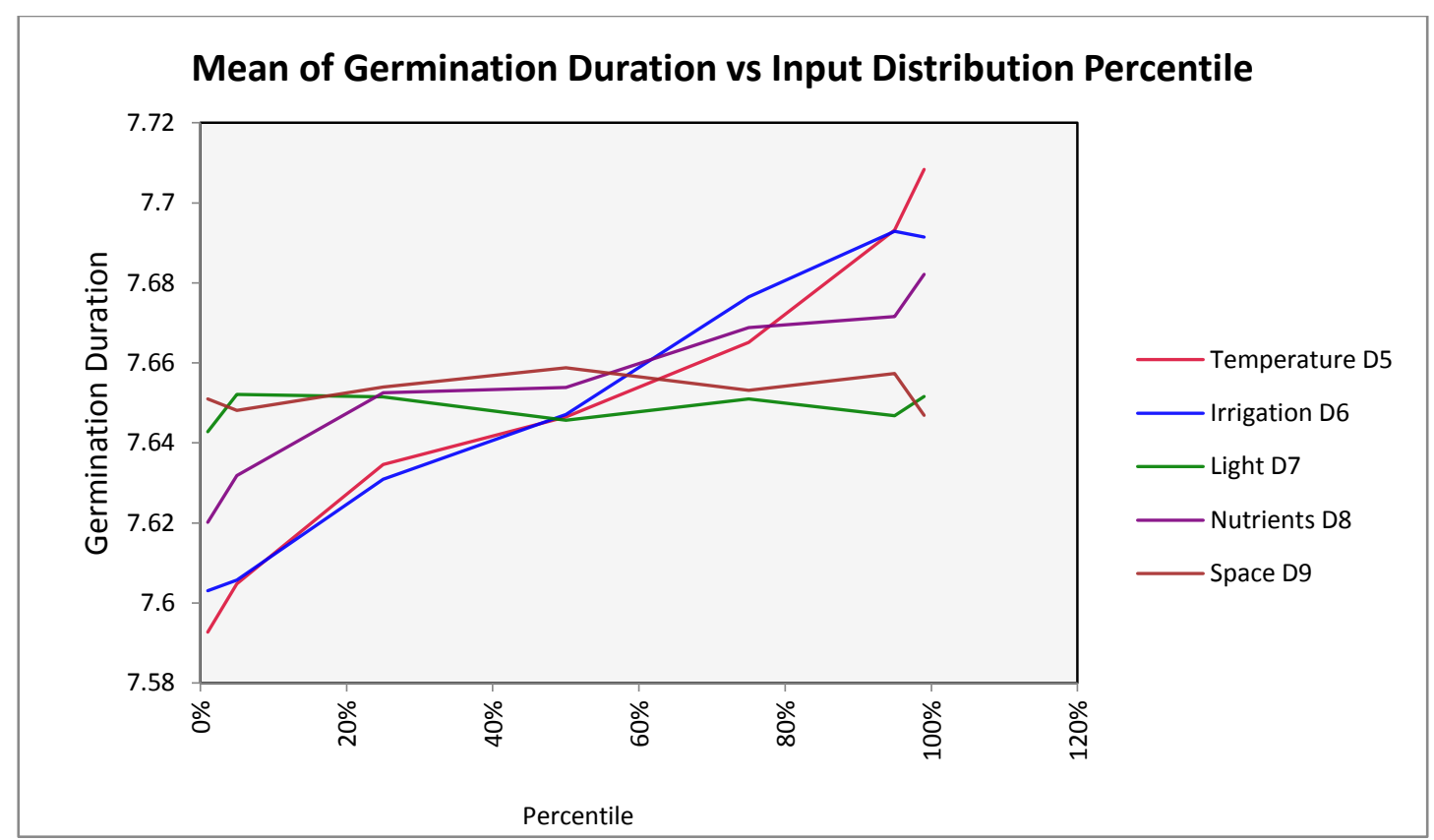

a)

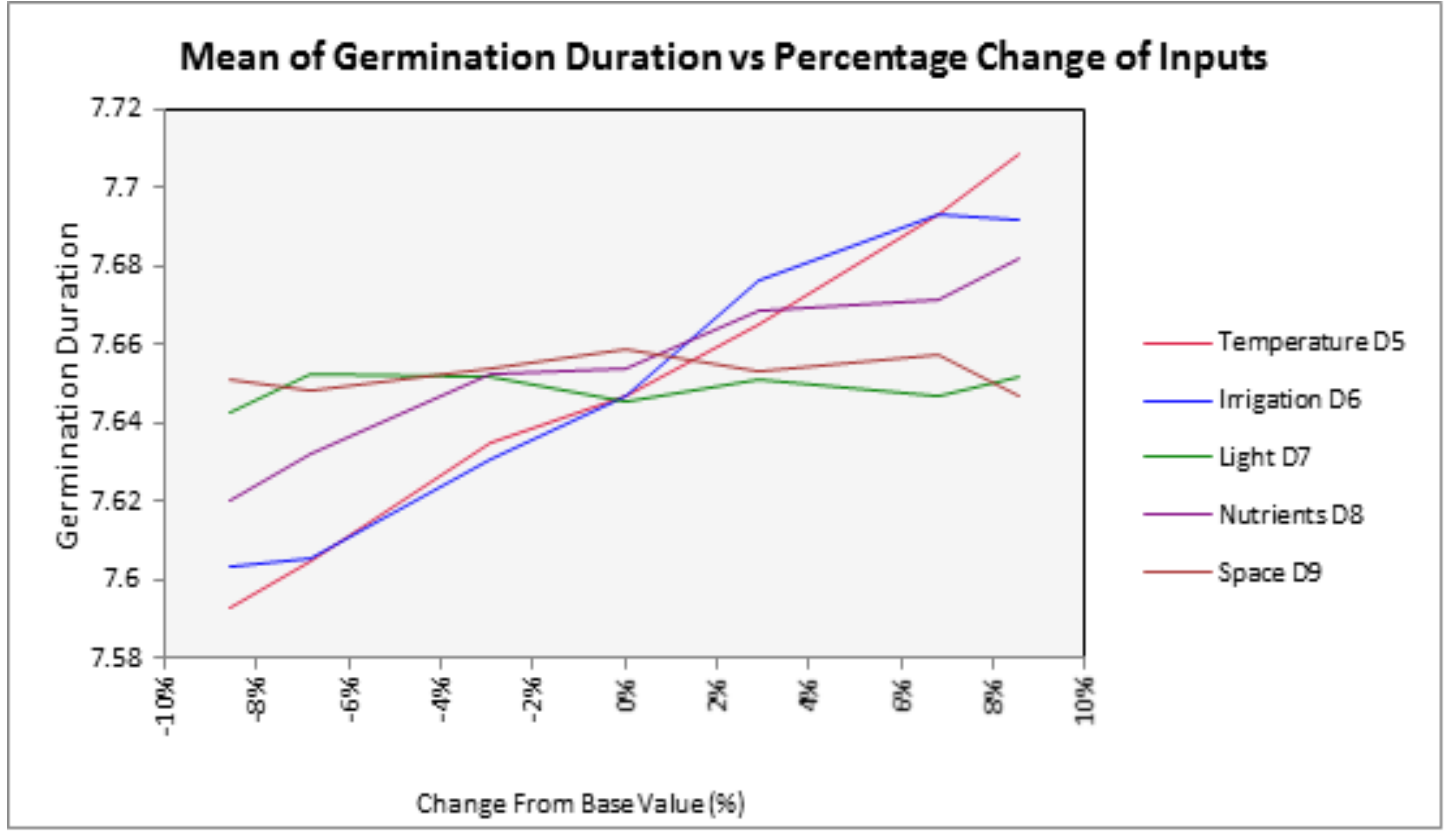

b)

Figure 13 Mean project duration vs change of Input factors

Plant-Environment analysis showed that plants have a strong dependency on their environment. Besides, it also revealed that their relationship modelling is complex but can be simulated. However, this basic relationship information is not available on building designing 
platforms that could help designers through the process right design for a building integrated agriculture or greenhouse. Therefore, the subsequent sections are focused on the development of the integration of building and plant data to a single platform, which has been referred as Building Integrated Agriculture information modelling (BIAIM).

\subsection{Visualisation and UI Development}

Visualisation has a major role in simulating the impact of environment on plants. For libraries and user interface development, Horticultural Classification of plants is selected, as shown in Figure 14, and the code sample is given in Appendix A. Autodesk Revit is chosen as a BIM platform to host the plugin. Revit has bi-directional open database connectivity, which makes it more versatile to manipulate the data even outside the BIM environment. Developed concept plugin has all environmental factors, which are discussed in section 3.1, and the data is saved to the local database on the computer. Figure 15 shows two different views of the UI: Revit Plugin; and plant library and real-time environmental properties. As neither Revit (BIM) nor developed database has plant information libraries, therefore, every time a new plant is created or loaded into the database, it requests for physical and environmental attributes to be uploaded. However, once the information is provided, it is saved to the database and would not be sought if the same species are placed at another location within the project.

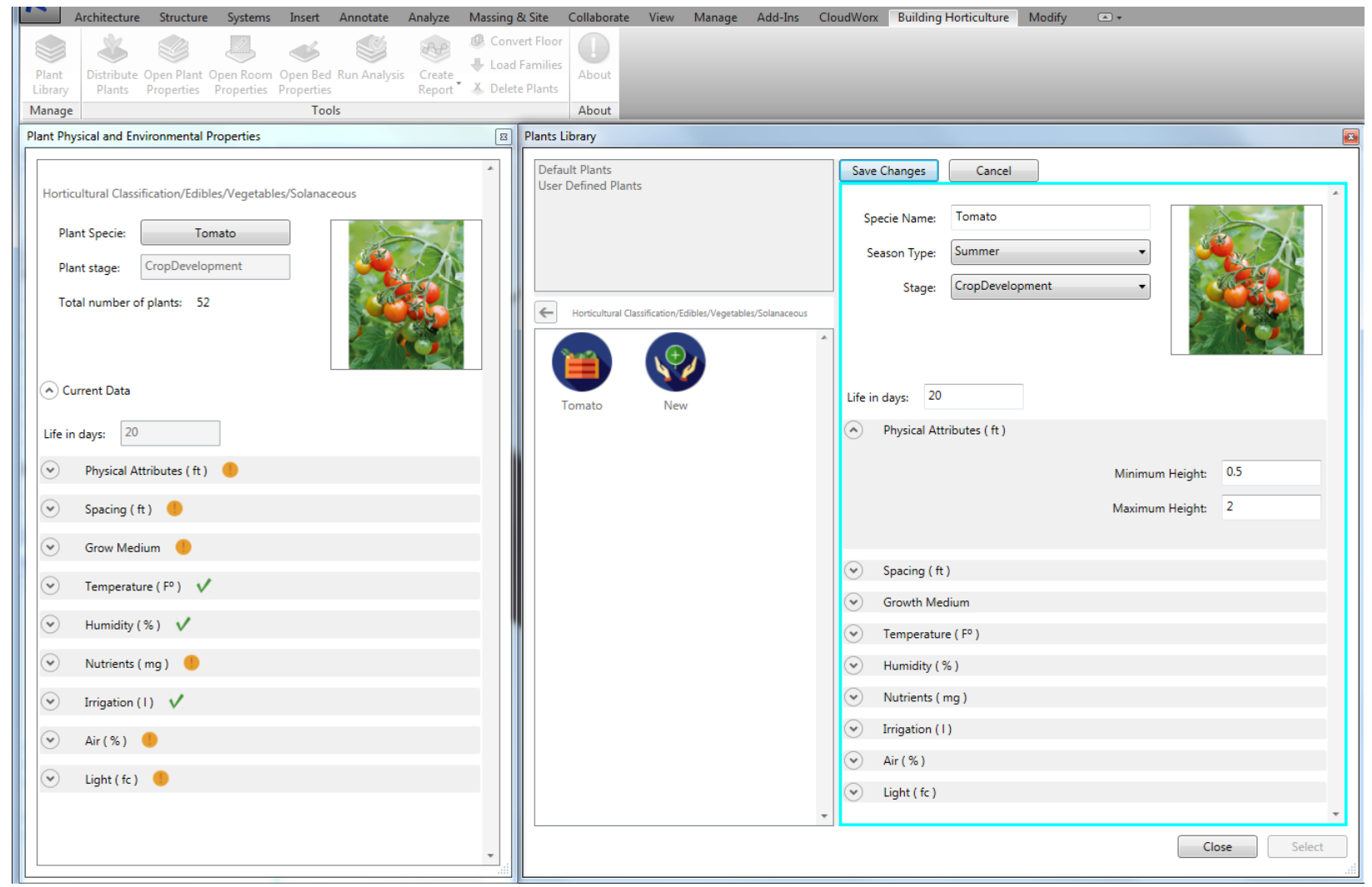




\subsection{Database-BIM Integration}

The project aims at the integration of BIA and BIM systems. A conceptual BIA database is developed because Revit (BIM) database cannot be manipulated to store the environmental factors and their impact on plants. In this case, BIM model hosts the client database, and all information is saved onto the developed database. With respect to that, the user interface helps to store and retrieve all the data, while database uses BIM environment for management and visualisation purposes.

The link between two databases can be done using objects unique IDs (UID). However, Revit does not have the ability to authorise the database manipulation using plant's UID. In this case, one of the possible solutions is to link the object libraries using their names. In that way, once a plant is loaded to the user database, the software checks provided a real-time condition on the application and will place the plants accordingly or generate warnings if the conditions are not suitable for plants. For example, Figure 15 shows that the software distributed tomato plants on a raised bed considering the available conditions. 52 plants are placed considering the available space. The red colour is due to the incompatible floor type, as the required medium is soil, but the selected medium is concrete.

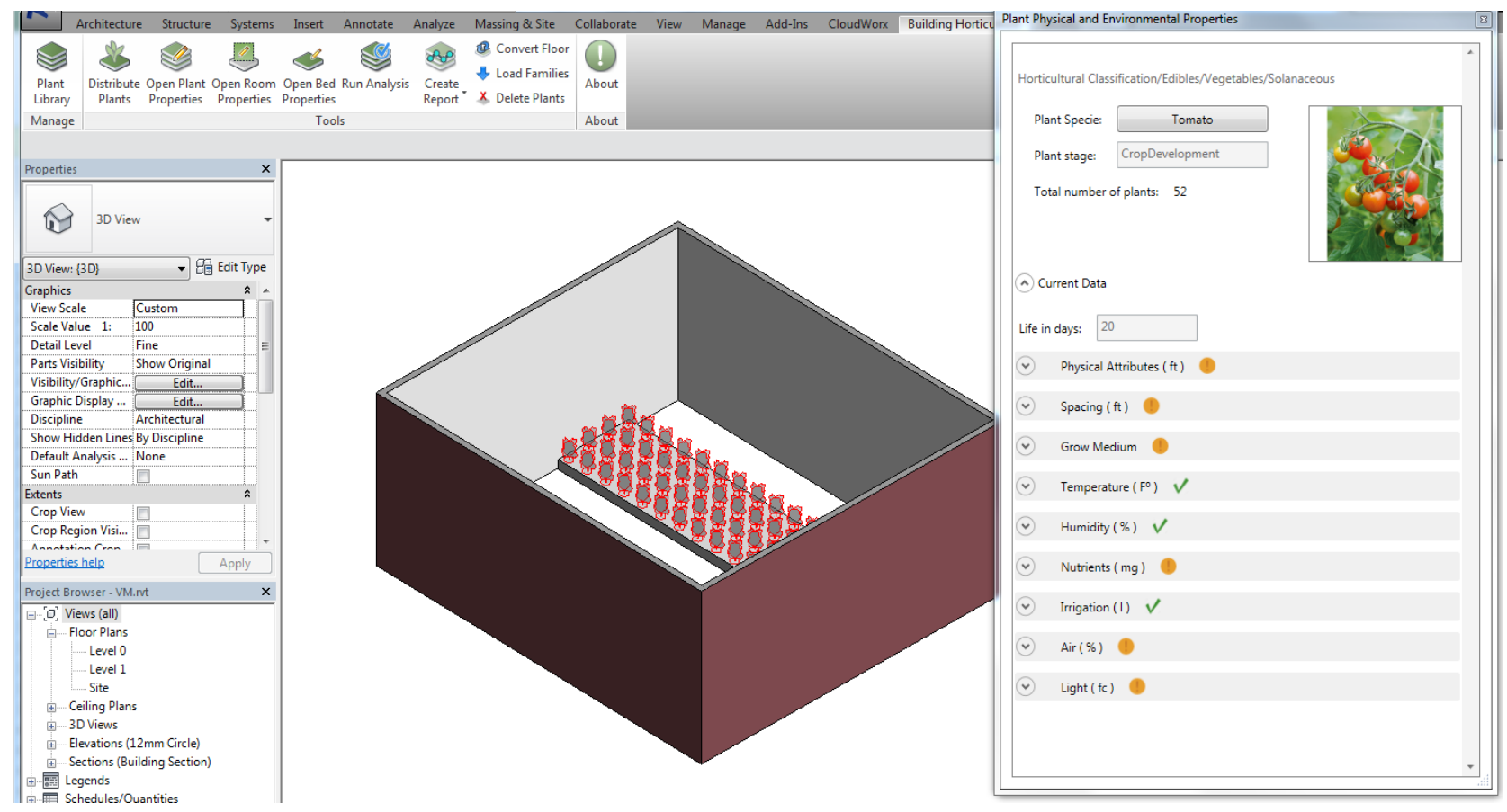

Figure 15 Plant distribution using BIAIM Plugin

\section{Discussion}

The agricultural industry is not only facing significant challenges at present, but its future is also very demanding. Meeting these challenges with the limited available resources is a current major challenge [107]. Whereas current methods are focusing on genetic stimulation, fertilisation, etc. [108]. Nonetheless, these techniques can only improve yield to a certain limit; while the increasing urbanisation and population challenges are more than just yield. 
Therefore, researchers and governing bodies are emphasising the need for new techniques and methods to meet these challenge [109]. As an alternative, the urban farming concept has reemerged and gained a significant amount of attention [110]. Though, in urban regions, due to limited space, BIA is a viable option [14]. While there are not any available tools to have P-E relationship information to design such facility. However, BIM tools have the potential to design such building and support through the entire process [24, 73]. The present research investigates BIA and BIM integration. The integration will facilitate the development of a novel system and may assist designers and planners to the state of BIM currently.

In this study, we analysed five environmental factors (temperature, water, light, macronutrients and spacing) that affect plants' life. The research also showed that BIA could help to save a considerable amount of resources; for example, irrigation losses are minimum in a CEA where there are no leaching requirements. However, as there is no direct ground water contribution or rainfall (for CEA crops), which indicates complete reliance on irrigation. The sensitivity analysis showed that a seedling would be germinated between 6 and 9 days; however, there is $90 \%$ probability that the seeds will germinate before day 8 . While under optimum conditions germination duration is 6 days [111]. The study has shown that a database containing environmental factors can be developed and linked to BIM tools. In this case, Autodesk Revit is used, and linking is done using object's name as Revit does not support UID [112]. The object shared the properties of both databases: BIM to host plants; developed a database to corresponding to the environmental factors.

BIM tools have effectively been used for planning, asset and space management, maintenance [33]. Like any other building, an agricultural building also contains these elements. Therefore, $\mathrm{BIM}$ is a powerful tool to design and manage BIA facility throughout its life. Though BIM and BIA integration have not been discussed in literature; however, its potential and demand exist; for example, BIM-based agricultural facilities $[34,54,57,105]$ will be difficult to design, manage and maintain in the absence of plant database.

Though the database is developed, however, analyses are limited to five factors. In addition, the database is only compatible with Autodesk Revit. The main limitation of the research is the requirement of the environmental factors, which can only be added to the developed database; not BIM database. Furthermore, it does not consider the real-time data integration at this stage. However, the plugin could be integrated with the sensors to capture real-time environmental data. Although the study only considered tomato crop; any other crop or plant can be added to the database. The development can considerably contribute to BIM level 3 and beyond; and to BIA information management. The plugin is of direct practical relevance and application.

\section{Conclusion and Future work}

This paper has presented a novel approach to integrating BIA to buildings using BIM design and management tool by developing a plugin. Results indicate that BIA and BIM can be integrated using database development and assigning computer readable rules. This further can be utilised for automated rule checking for optimum environmental conditions. New platform and method were developed to automatically analyse environmental conditions for plants in a BIMintegrated environment, which has successfully been integrated. The performed research 
illustrates that BIA planning can effectively be done with the help of BIA-BIM integration. Analysis showed that there would be less waste of resources, e.g. water, nutrients in a BIA, and other factors like temperature and light can be managed effectively using both natural and artificial lighting. Similarly, sensitivity analysis showed that growth could be optimised by providing an optimum condition. This tool differs from existing approaches in that it will engage many stakeholders from designers to facility managers who are involved in the design and management of that facility. Especially, it will help designers and planners at an early stage to design BIA facilities using BIM smart designing tools, which already have proven its benefits to the AEC industry.

This paper is a part of an ongoing doctoral research. Future work will entail the detailed development of software, testing and validation in real-time conditions, and evaluation which will stimulate all environmental factors and their impact on plants in real life conditions.

\section{References}

1. Tomato Nutritional Summary / Yara. 2015; Available from: http://www.yara.us/agriculture/crops/tomato/key-facts/nutritional-summary/.

2. Extension, C.S.U., Colorado State University Extension / Information you can use. 2014.

3. Cohen, B., Urbanization in developing countries: Current trends, future projections, and key challenges for sustainability. Technology in Society, 2006. 28(1-2): p. 63-80.

4. Emmanuel, R., Thermal comfort implications of urbanization in a warm-humid city: The Colombo Metropolitan Region (CMR), Sri Lanka. Building and Environment, 2005. 40(12): p. 1591-1601.

5. Emmanuel, R., H. Rosenlund, and E. Johansson, Urban shading - A design option for the tropics? A study in Colombo, Sri Lanka. International Journal of Climatology, 2007. 27(14): p. 1995-2004.

6. Kong, L., et al., Regulation of outdoor thermal comfort by trees in Hong Kong. Sustainable Cities and Society, 2017. 31: p. 12-25.

7. Indraprahasta, G.S., The Potential of Urban Agriculture Development in Jakarta. Procedia Environmental Sciences, 2013. 17: p. 11-19.

8. Siciliano, G., Rural-Urban Migration and Domestic Land Grabbing in China. Population, Space and Place, 2014. 20(4): p. 333-351.

9. Khalif, A. and A. Nur, The African Farmer and the Challenge of Food Security in Africa. Development, 2013. 56(2): p. 257-265.

10. Yu, Y., et al., Global Implications of China's Future Food Consumption. Journal of Industrial Ecology, 2016. 20(3): p. 593-602. 
11. Riffat, S., R. Powell, and D. Aydin, Future cities and environmental sustainability. Future Cities and Environment, 2016. 2(1): p. 1.

12. Wang, T., et al., Integration of solar technology to modern greenhouse in China: Current status, challenges and prospect. Renewable and Sustainable Energy Reviews, 2017. 70: p. 1178-1188.

13. Panwar, N.L., S.C. Kaushik, and S. Kothari, Solar greenhouse an option for renewable and sustainable farming. Renewable and Sustainable Energy Reviews, 2011. 15(8): p. 3934-3945.

14. Despommier, D., Farming up the city: the rise of urban vertical farms. Trends in Biotechnology, 2013. 31(7): p. 388-389.

15. Willaarts, B., I. Pardo, and G.d.I. Mora, Urbanization, socio-economic changes and population growth in Brazil: dietary shifts and environmental implications. 2013.

16. Indraprahasta, G.S. and I. Agustina, URBAN AGRICULTURE ACTIVITY AND ITS POTENTIALS TO ERADICATE URBAN POVERTY IN JAKARTA. 2016, 2016. 14(3): p. 15.

17. Game, I. and R. Primus, GSDR 2015 Brief Urban Agriculture. 2015.

18. Benis, K. and P. Ferrão, Potential mitigation of the environmental impacts of food systems through urban and peri-urban agriculture (UPA) - a life cycle assessment approach. Journal of Cleaner Production, 2017. 140, Part 2: p. 784-795.

19. Hall, G., et al., Potential environmental and population health impacts of local urban food systems under climate change: a life cycle analysis case study of lettuce and chicken. Agriculture \& Food Security, 2014. 3(1): p. 6.

20. Wielemaker, R.C., J. Weijma, and G. Zeeman, Harvest to harvest: Recovering nutrients with New Sanitation systems for reuse in Urban Agriculture. Resources, Conservation and Recycling, 2016.

21. Dvorsky, G., How Vertical Farming is Revolutionizing the Way We Grow Food, in Daily Explainer. 2015, @io9.

22. Hong, G.-Z. and C.-L. Hsieh, Application of Integrated Control Strategy and Bluetooth for Irrigating Romaine Lettuce in Greenhouse. IFAC-PapersOnLine, 2016. 49(16): p. 381-386.

23. SketchUp for Architecture. 2017 [cited $2017 \quad 19$ 03]; Available from: https://www.sketchup.com/3Dfor/architecture.

24. Revit for arcitectural design. 2017 [cited 201719 03]; Available from: http://www.autodesk.com/products/revit-family/architecture.

25. All about ARCHICAD. 2017 [cited 201719 03]; Available from: http://archicad.com/en/all-aboutarchicad/. 
26. Silverman, J. HowStuffWorks "Will there be farms in New York City's skyscrapers?". 2017 [cited 2017 01/03]; Available from: http://science.howstuffworks.com/environmental/conservation/issues/vertical-farming.htm.

27. Peckienè, A. and L. Ustinovičius, Possibilities for Building Spatial Planning using BIM Methodology. Procedia Engineering, 2017. 172: p. 851-858.

28. Shen, W., Q. Shen, and Q. Sun, Building Information Modeling-based user activity simulation and evaluation method for improving designer-user communications. Automation in Construction, 2012. 21(0): p. 148-160.

29. RICS. What is BIM? 2014 [cited 201703 06]; Available from: http://www.rics.org/uk/knowledge/glossary/bim-intro/.

30. Singh, I., BIM adoption around the world: Initiatives by major nations, in Geospatial world. 2017, Geospatial world.

31. Kubba, S., Chapter Five - Building Information Modeling (BIM), in Handbook of Green Building Design and Construction (Second Edition). 2017, Butterworth-Heinemann. p. 227-256.

32. NBS, National BIM Report 2016 / NBS. 2017, NBS: UK.

33. Ghaffarianhoseini, A., et al., Building Information Modelling (BIM) uptake: Clear benefits, understanding its implementation, risks and challenges. Renewable and Sustainable Energy Reviews, 2016.

34. Institute, L., BIM for landscape. 2016, London : Routledge.

35. Succar, B., Building information modelling framework: A research and delivery foundation for industry stakeholders. Automation in Construction, 2009. 18(3): p. 357-375.

36. Succar, B., W. Sher, and A. Williams, An integrated approach to BIM competency assessment, acquisition and application. Automation in Construction, 2013. 35(0): p. 174-189.

37. Bouška, R., Evaluation of Maturity of BIM Tools across Different Software Platforms. Procedia Engineering, 2016. 164: p. 481-486.

38. Goldstein, B., et al., Surveying the Environmental Footprint of Urban Food Consumption. Journal of Industrial Ecology, 2017. 21(1): p. 151-165.

39. Goldstein, B., et al., Testing the environmental performance of urban agriculture as a food supply in northern climates. Journal of Cleaner Production, 2016. 135: p. 984-994.

40. Nyantakyi-Frimpong, H., G. Arku, and D.K.B. Inkoom, Urban agriculture and political ecology of health in municipal Ashaiman, Ghana. Geoforum, 2016. 72: p. 38-48.

41. Choguill, C.L., Urban agriculture and cities in the developing world. 1995. 19(2): p. 149-150. 
42. Martellozzo, F., et al., Urban agriculture: a global analysis of the space constraint to meet urban vegetable demand. Environmental Research Letters, 2014. 9(6): p. 064025.

43. Moglia, M., Urban agriculture and related water supply: Explorations and discussion. Habitat International, 2014. 42(0): p. 273-280.

44. dos Santos, M.J.P.L., Smart cities and urban areas-Aquaponics as innovative urban agriculture. Urban Forestry \& Urban Greening, 2016. 20: p. 402-406.

45. Ackerman, K., 7 - Urban agriculture: opportunities and constraints, in Metropolitan Sustainability, F. Zeman, Editor. 2012, Woodhead Publishing. p. 118-146.

46. Cuce, E., D. Harjunowibowo, and P.M. Cuce, Renewable and sustainable energy saving strategies for greenhouse systems: A comprehensive review. Renewable and Sustainable Energy Reviews, 2016. 64: p. 34-59.

47. Chauhan, P.S., A. Kumar, and B. Gupta, A review on thermal models for greenhouse dryers. Renewable and Sustainable Energy Reviews.

48. Esen, M. and T. Yuksel, Experimental evaluation of using various renewable energy sources for heating a greenhouse. Energy and Buildings, 2013. 65: p. 340-351.

49. Kumar, K.S., et al., Modeling and evaluation of greenhouse for floriculture in subtropics. Energy and Buildings, 2010. 42(7): p. 1075-1083.

50. Vadiee, A. and V. Martin, Energy analysis and thermoeconomic assessment of the closed greenhouse - The largest commercial solar building. Applied Energy, 2013. 102: p. 1256-1266.

51. Vadiee, A., et al., Energy analysis of fuel cell system for commercial greenhouse application - A feasibility study. Energy Conversion and Management, 2015. 89: p. 925-932.

52. Groener, B., et al., Preliminary Design of a Low-cost Greenhouse with Open Source Control Systems. Procedia Engineering, 2015. 107: p. 470-479.

53. Dunn, T., See 9 stunning vertical farms that could solve the planet's food crisis. 2017.

54. Vyawahare, M., World's largest vertical farm grows without soil, sunlight or water in Newark. 2016.

55. Gould, D. and T. Caplow, 8 - Building-integrated agriculture: a new approach to food production A2 - Zeman, Frank, in Metropolitan Sustainability. 2012, Woodhead Publishing. p. 147-170.

56. Vertical Farming. 2015 [cited 201719 03]; Available from: http://grow.verticrop.com/verticalfarming/. 
57. Alter, L. Real Live Vertical Farm Built In South Korea, Churning Out Lettuce. 2011 [cited 201719 03]; Available from: http://www.treehugger.com/green-food/real-live-vertical-farm-built-insouth-korea-churning-out-lettuce.html.

58. This Japanese Vertical Farming Company Wants to Grow Your Lettuce. 2017 [cited 201706 06]; Available from: http://agritecture.com/post/27440882258/nuvege.

59. Vertical Farming. 2017 [cited 201612 12]; Available from: http://www.skygreens.com/aboutskygreens/.

60. Robarts, S. FarmedHere has high ambitions with new 60,000 sq ft vertical farm. 2016 [cited 201719 03]; Available from: http://newatlas.com/farmedhere-vertical-farm-west-louisvillefoodport/41569/.

61. Benis, K., C. Reinhart, and P. Ferrão, Development of a simulation-based decision support workflow for the implementation of Building-Integrated Agriculture (BIA) in urban contexts. Journal of Cleaner Production, 2017. 147: p. 589-602.

62. Sabeh, N., Chapter 6 - Rooftop Plant Production Systems in Urban Areas A2 - Kozai, Toyoki, in Plant Factory, G. Niu and M. Takagaki, Editors. 2016, Academic Press: San Diego. p. 105-111.

63. Specht, K. and E. Sanyé-Mengual, Risks in urban rooftop agriculture: Assessing stakeholders' perceptions to ensure efficient policymaking. Environmental Science \& Policy, 2017. 69: p. 13-21.

64. Specht, K., et al., Urban agriculture of the future: an overview of sustainability aspects of food production in and on buildings. Agriculture and Human Values, 2014. 31(1): p. 33-51.

65. Pons, O., et al., Roofs of the Future: Rooftop Greenhouses to Improve Buildings Metabolism. Procedia Engineering, 2015. 123: p. 441-448.

66. Maia, L., P. Mêda, and J.G. Freitas, BIM Methodology, a New Approach - Case Study of Structural Elements Creation. Procedia Engineering, 2015. 114: p. 816-823.

67. Habibi, S., The Promise of BIM for Improving Building Performance. Energy and Buildings, 2016.

68. Ahuja, R., A. Sawhney, and M. Arif, Driving lean and green project outcomes using BIM: A qualitative comparative analysis. International Journal of Sustainable Built Environment, 2017. 6(1): p. 69-80.

69. Bradley, A., et al., BIM for infrastructure: An overall review and constructor perspective. Automation in Construction, 2016. 71: p. 139-152.

70. Ghaffarianhoseini, A., et al., Building Information Modelling (BIM) uptake: Clear benefits, understanding its implementation, risks and challenges. Renewable and Sustainable Energy Reviews, 2017. 75: p. 1046-1053. 
71. Love, P.E.D., et al., A benefits realization management building information modeling framework for asset owners. Automation in Construction, 2014. 37: p. 1-10.

72. Zhang, X., et al., Understanding the users' continuous adoption of 3D social virtual world in China: A comparative case study. Computers in Human Behavior, 2014. 35: p. 578-585.

73. About ARCHICAD Q?" A 3D architectural BIM software for design \&amp; modeling. 2017 [cited 2017 01/02]; Available from: http://www.graphisoft.com/archicad/.

74. Revit Family. 2017 [cited 201706 03]; Available from: http://www.autodesk.co.uk/products/revit-family/overview.

75. Kim, $\mathrm{H}$., et al., BIM IFC information mapping to building energy analysis (BEA) model with manually extended material information. Automation in Construction, 2016. 68: p. 183-193.

76. Capellini, D. 5 Terre Vertical Farm Concept Addresses Urban Population Growth / GAB Report. 2013 [cited 2017 18/03/2017]; Available from: http://www.gabreport.com/2013/12/5-terrevertical-farm-concept-addresses-urban-population-growth.

77. Barlish, K. and K. Sullivan, How to measure the benefits of BIM - A case study approach. Automation in Construction, 2012. 24: p. 149-159.

78. Blanco, F.G.B. and H. Chen, The Implementation of Building Information Modelling in the United Kingdom by the Transport Industry. Procedia - Social and Behavioral Sciences, 2014. 138: p. 510520.

79. Porwal, A. and K.N. Hewage, Building Information Modeling (BIM) partnering framework for public construction projects. Automation in Construction, 2013. 31(0): p. 204-214.

80. Larjosto, V. and P. Raivio, Dodo farming urban vegetable gardens in Helsinki. Territorio, 2012. 60: p. 44-48.

81. FARMTECTURE. 2016 [cited 201701 03]; Available from: http://www.capelliniarchitects.com/archive/Brochure/Brochure\%20FARMTECTURE.pdf.

82. Environmental Factors Influencing Vegetable Crop Growth and Production - lecture2.pdf. 2015; Available from: http://aesop.rutgers.edu/ horteng/workshop/lecture2.pdf.

83. Ames, M.J., S., Wayne., Hydrofarm - A Review of Factors Affecting Plant Growth. 2015.

84. AZ Master Gardener Manual: Environmental Factors. 2015; Available from: https://ag.arizona.edu/pubs/garden/mg/botany/environmental.html.

85. Commercial Gallery / Keder Greenhouse. 2015; Available from: http://www.kedergreenhouse.co.uk/Commercial-Gallery.html. 
86. Growing Indoor Plants with Success / Publications / UGA Extension. 2015; Available from: http://extension.uga.edu/publications/detail.cfm?number=B1318.

87. Wang, W., et al., Applications of terrestrial laser scanning for tunnels: a review. Journal of Traffic and Transportation Engineering (English Edition), 2014. 1(5): p. 325-337.

88. Decoteau, D., Plant Physiology: Environmental Factors and Photosynthesis, in Greenhouse Glazing \& Solar Radiation Transmission Workshop, Oct ober 1998. 1998, Rutgers University: CCEA, Center for Controlled Environment Agriculture, Rutgers University, Cook College.

89. Burrell, C., C., Vegetable Spacing Guide - HowStuffWorks. 2015, @HowStuffWorks.

90. University, C. Explore Cornell - Home Gardening - Vegetable Growing Guides - Growing Guide. 2017 [cited $2017 \quad 04 \quad$ 06]; Available from: http://www.gardening.cornell.edu/homegardening/sceneea10.html\#growinginfo.

91. P. Savva, A. and K. Frenken, Crop water requirement and irrigation scheduling, FAO, Editor. 2002, FAO: Harare. p. 122.

92. Allen, R.G., et al., Crop evapotranspiration - Guidelines for computing crop water requirements FAO Irrigation and drainage. 1998, FAO: Rome.

93. Pamungkas, A.P., K. Hatou, and T. Morimoto, Evapotranspiration Model Analysis of Crop Water Use in Plant Factory System. Environmental Control in Biology, 2014. 52(3): p. 183-188.

94. SFGATE. Do Tomato Plants Prefer Morning or Afternoon Sun. 2017 [cited 1; Available from: http://homeguides.sfgate.com/tomato-plants-prefer-morning-afternoon-sun-57922.html.

95. Rhoades, H. What Are The Light Requirements For Tomato Plants. 2009 2009-03-06T20:50:4104:00 [cited $2017 \quad 14 \quad 06$ ] 14 Available from: https://www.gardeningknowhow.com/edible/vegetables/tomato/how-much-sun-do-tomatoplants-need.htm.

96. Mattson, N., Greenhouse Lighting, in Cornell Greenhouse Horticulture. 2017, Cornell University. p. 1-6.

97. Morgan, L., Hydroponic Illumination \& the Daily Light Integral. 2016, Maximum Yield.

98. Rhoades, H., Plant Spacing Guide - Information On Proper Vegetable Garden Spacing. 2013.

99. Dupont, S., Tiana. Seed and Seedling Biology (Start Farming). 2017 [cited 2017 10/03]; Available from: $\quad$ http://extension.psu.edu/business/start-farming/vegetables/factsheets/seed-andseedling-biology.

100. Growing plants. 2017 [cited 201707 03]; Available from: http://www.bbc.co.uk/bitesize/standard/biology/world of plants/growing plants/revision/2/. 
101. Batty, D. Effect of Light on Germination and Seedlings / Thompson \&amp; Morgan. 2017 [cited 201718 03]; Available from: http://www.thompson-morgan.com/effect-of-light.

102. Requirements for Seed Germination. 2017 [cited 201718 03]; Available from: http://theagricos.com/seed-technology/seed-germination/requirements-for-seed-germination/.

103. Controlled Environment Agriculture. 2012 [cited 201720 03]; Available from: https://projectne.thomsonreuters.com/\#/login?referrer=\%252F\%23\%252Flogin\%3Fapp\%3Dend note\&app=endnote\&pageview $=$.

104. Jaeger, M. and P.H. De Reffye, Basic concepts of computer simulation of plant growth. Journal of Biosciences, 1992. 17(3): p. 275-291.

105. Prusinkiewicz, P., Modeling plant growth and development. Current Opinion in Plant Biology, 2004. 7(1): p. 79-83.

106. Merks, R.M.H., et al., VirtualLeaf: An Open-Source Framework for Cell-Based Modeling of Plant Tissue Growth and Development. 2011.

107. Davis, K.F., et al., Meeting future food demand with current agricultural resources. Global Environmental Change, 2016. 39: p. 125-132.

108. Huang, J. and G. Yang, Understanding recent challenges and new food policy in China. Global Food Security, 2017. 12: p. 119-126.

109. Conforti, P. Looking Ahead in World Food and Agriculture: Perspectives to 2050 - i2280e.pdf. 2015; Available from: http://www.fao.org/docrep/014/i2280e/i2280e.pdf.

110. Lu, C. and S. Grundy, Urban Agriculture and Vertical Farming A2 - Abraham, Martin A, in Encyclopedia of Sustainable Technologies. 2017, Elsevier: Oxford. p. 393-402.

111. Junior, J.B.J., Tomato Plant Culture. Second ed. In the Field, Greenhouse and Home Garden. 2007, New York: CRC Press, Taylor and Francis Group.

112. Autodesk. My First Revit Plug-in Overview. 2017 [cited 201705 06]; Available from: http://usa.autodesk.com/adsk/servlet/index?sitelD=123112\&id=16777469.

113. Capellini, D. 5 Terre Vertical Farm Concept Addresses Urban Population Growth / GAB Report. 2014 [cited 201718 03]; Available from: http://www.gabreport.com/2013/12/5-terre-verticalfarm-concept-addresses-urban-population-growth. 


\section{Appendix A}

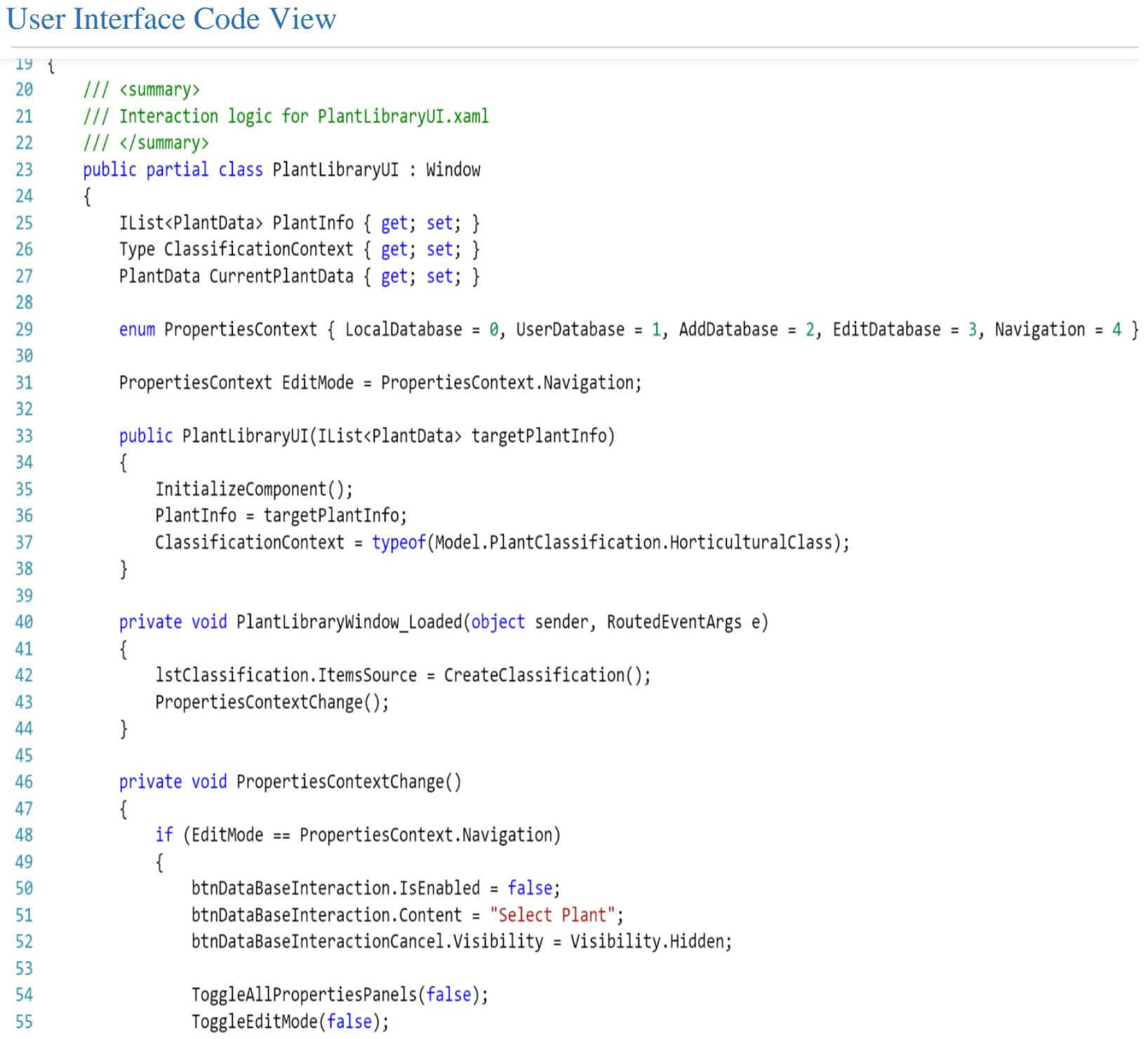




\section{Horticultural Classification View}

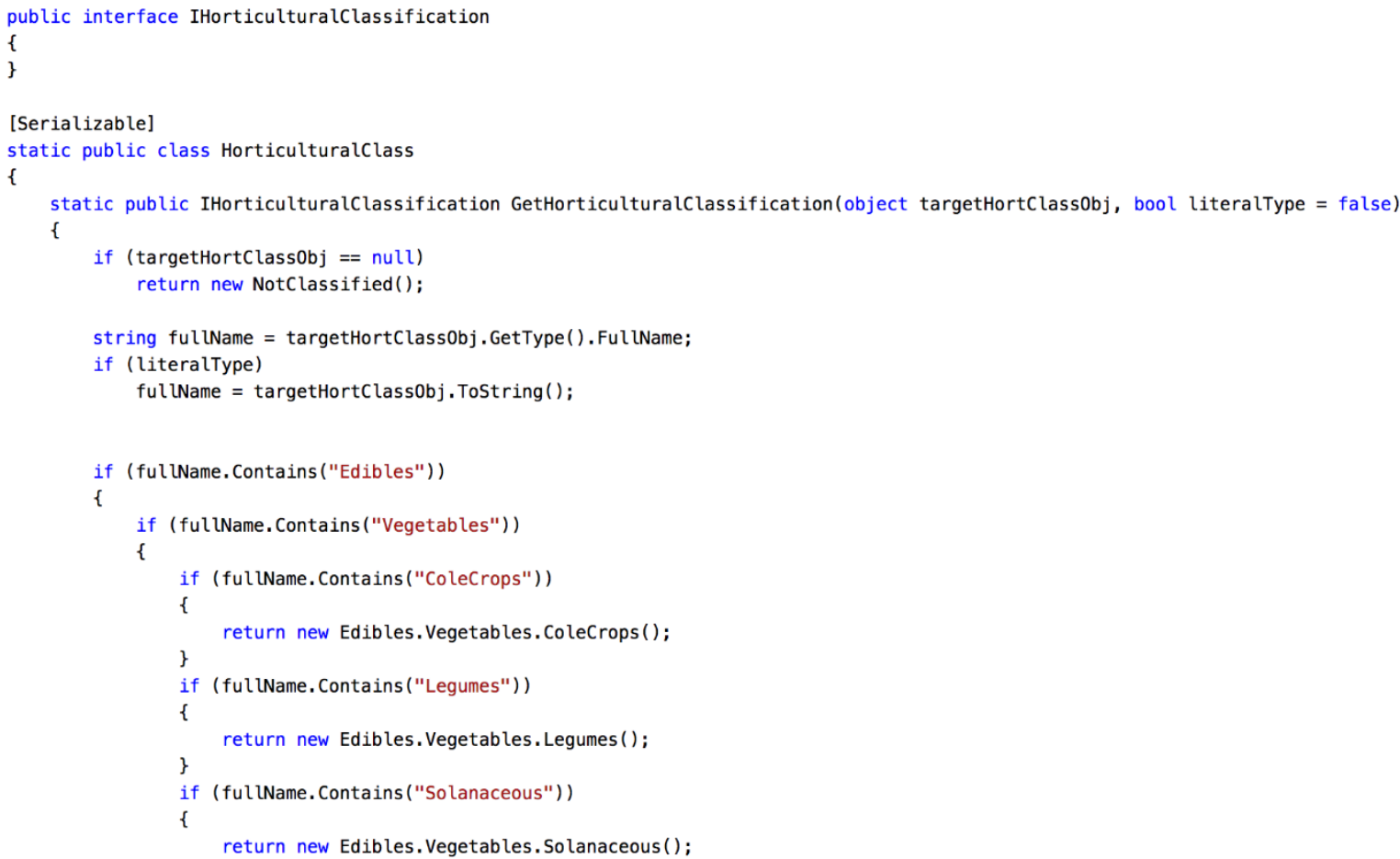

